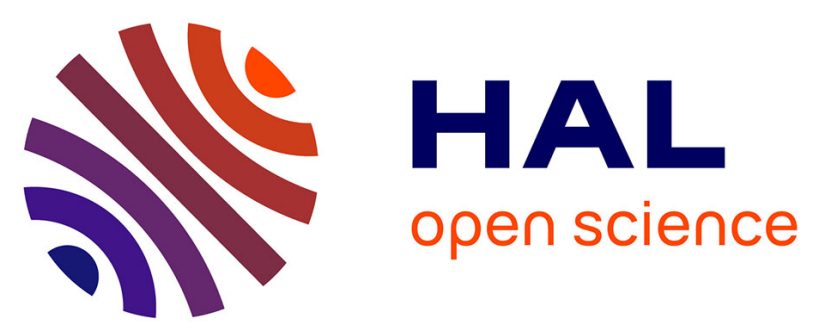

\title{
SAHARAN DUST ON FUERTEVENTURA ISLAND (CANARIES): CHEMICAL AND MINERALOGICAL CHARACTERISTICS, AIR MASS TRAJECTORIES, AND PROBABLE SOURCES
}

G Coude-Gaussen, Pierre Rognon, G. Bergametti, L Gomes, B. Strauss, J. M. Gros, M N Le Coustumer

\section{To cite this version:}

G Coude-Gaussen, Pierre Rognon, G. Bergametti, L Gomes, B. Strauss, et al.. SAHARAN DUST ON FUERTEVENTURA ISLAND (CANARIES): CHEMICAL AND MINERALOGICAL CHARACTERISTICS, AIR MASS TRAJECTORIES, AND PROBABLE SOURCES. Journal of Geophysical Research: Atmospheres, 1987, 92 (D8), pp.9753-9771. 10.1029/JD092iD08p09753 . hal-02326755

\section{HAL Id: hal-02326755 https://hal.science/hal-02326755}

Submitted on 22 Oct 2019

HAL is a multi-disciplinary open access archive for the deposit and dissemination of scientific research documents, whether they are published or not. The documents may come from teaching and research institutions in France or abroad, or from public or private research centers.
L'archive ouverte pluridisciplinaire HAL, est destinée au dépôt et à la diffusion de documents scientifiques de niveau recherche, publiés ou non, émanant des établissements d'enseignement et de recherche français ou étrangers, des laboratoires publics ou privés. 
SAHARAN DUST ON FUERTEVENTURA ISLAND (CANARIES): CHEMICAL AND MINERALOGICAL CHARACTERISTICS, AIR MASS TRAJECTORIES, AND PROBABLE SOURCES

\author{
G. Coude-Gaussen, ${ }^{1}$ P. Rognon, ${ }^{1}$ G. Bergametti, ${ }^{2}$ L. Gomes, ${ }^{2}$ B. Strauss, ${ }^{3}$ \\ J. M. Gros, ${ }^{3}$ and M. N. Le Coustumer 4
}

Abstract. From April 12 to 19, 1984, dust was collected by cascade impactor on Fuerteventura Island, $100 \mathrm{~km}$ from the Saharan coast. The samples were analyzed by $X$ ray fluorescence spectrometry (elemental composition), by $X$ ray diffraction (mineral constituents), and by scanning electron microscope (SEM) and energy dispersive $X$ ray analyzer (EDXA) examination (shape, surface features, and mineralogy of particles), with the aim of determining the possible source areas of the dust. On the scale of dust clouds, another method allowed us to define the displacements of the dust: using remote sensing (METEOSAT II, National Oceanic and Atmospheric Administration (NOAA)) and computing trajectories for any starting or ending point at any time. These various methods gave complementary results and pointed out two successive episodes of dust with two different continental origins. The first originated from a nearby source in the Souss plain (southern Morocco) and was characterized by very fine quartz particles. The second drifted above more remote calcareous regions. This study allows us to show how different methods can be used to characterize dust and to find the source areas. The results suggest some general questions about the occurrence of coarse particles in the atmosphere and their role in the atmospheric deposition flux budget.

\section{Introduction}

So far, the studies on Saharan dust have mostly concerned the trajectories from the Sahelian belt to either the Gulf of Guinea [Bertrand et al., 1974; Domergue, 1980] or the Caribbean Sea [Carlson and Prospero, 1972; Glaccum and Prospero, 1980; Schütz, 1980; Morales, 1979]. The authors chiefly gave data on the size distribution [Schütz and Jaenicke, 1974; Lepple, 1975; Jaenicke, 1978; D'Almeida and Schütz, 1983], mineralogy [Lange, 1982] and geochemistry [Delany et al., 1967; Rahn et al., 1976] of the dust particles and their effects upon the optical properties of the atmosphere [Carlson, 1979; Carlson and Benjamin, 1980]. These studies have pointed out the possible contribution of dust to the present or Quaternary oceanic sedimentation

1 Unité Associée 722, Centre National de la Recherche Scientifique, Université Plerre et Marle Curie, Paris, France.

2 Laboratoire de Physico-Chimle de 1 'Atmosphère, Université Paris VII, Paris, France.

3 Météorologie Nationale, Paris, France.

4 Centre de Géomorphologie du Centre National de 1a Recherche Scientifique, Caen, France.

Copyright 1987 by the American Geophysical Union.

Paper number 7D0504.

0148-0227/87/007D-0504\$05.00
[Windom, 1975; Chester et al., 1979; Sarnthein et al., 1982] and, probably, to the mineral feeding of marine plankton. The dust outbreaks from northwestern Africa to the middle Atlantic and Western Europe have been much less studied. The only samplings were carried out during oceanic cruises [Chester and Johnson, 1971; Parkin et al., 1972] and the results were compared to the marine sedimentation [Tetzlaff and Wolter, 1980; Sarnthein et al., 1982]. On the other hand, the fallout on the islands was not considered, except in a short note about the sampling of dust on Tenerife island [Fernandez-Navarro, 1921] and another about the dust effects upon the underground water chemistry in the Gran Canaria [Logan, 1974].

A research project, supported by the French Centre National de la Recherche Scientifique (CNRS), started with the purpose of characterizing Saharan dust [Coudé-Gaussen, 1982, 1984; Coudé-Gaussen and Rognon, 1983]. Fuerteventura Island (eastern Canaries) is a particularly interesting area for this study because aeolian particles have been encountered in various silty deposits of surface formations: desert quartz, allochthonous minerals, feltlike grains of $f i-$ brous clays, etc. [Chamley et al., 1987]. Relating to this project, dust samples were collected from Apri1 12 to 19, 1984, on Fuerteventura Island. This island is $100 \mathrm{~km}$ from the Saharan coast and, at that distance, the dust clouds become a little more homogeneous than over the source regions. Factory or city pollution is very scarce on this island. Moreover, the mineral assemblage coming from its volcanic substratum would be very different from ones of possible Saharan origin. The island climate is characterized by varied weather systems which are favorable to Saharan dust transport. In winter, Fuerteventura is on the southern boundary of cyclonic tracks. In the intermediate seasons the island is on the trajectories of the polar outbreaks or tropical thunderstorms along the discontinuities between marine and continental tropical air masses. Finally, in winter or in summer the socalled "Levante" wind may blow from southern Morocco toward the Canarles. So, Saharan aerosols may be brought over Fuerteventura Island any time during the year, as has been shown by both climatic data [Huetz de Lemps, 1969] and a statistical study on the year 1979 from the imagery given by the GOES East and METEOSAT satellites [01iva et al., 1983].

Our study tries to connect five distinct branches of natural science: chemlstry, mineralogy, micromorphology, atmospheric physics, and remote sensing. The complementary results are very useful to understand the "behavior" of dust. Thanks to these various methods, it is also possible to consider the different scales from the elementary particle to the dust cloud.

Chemical composition, mineralogy, and morpho- 


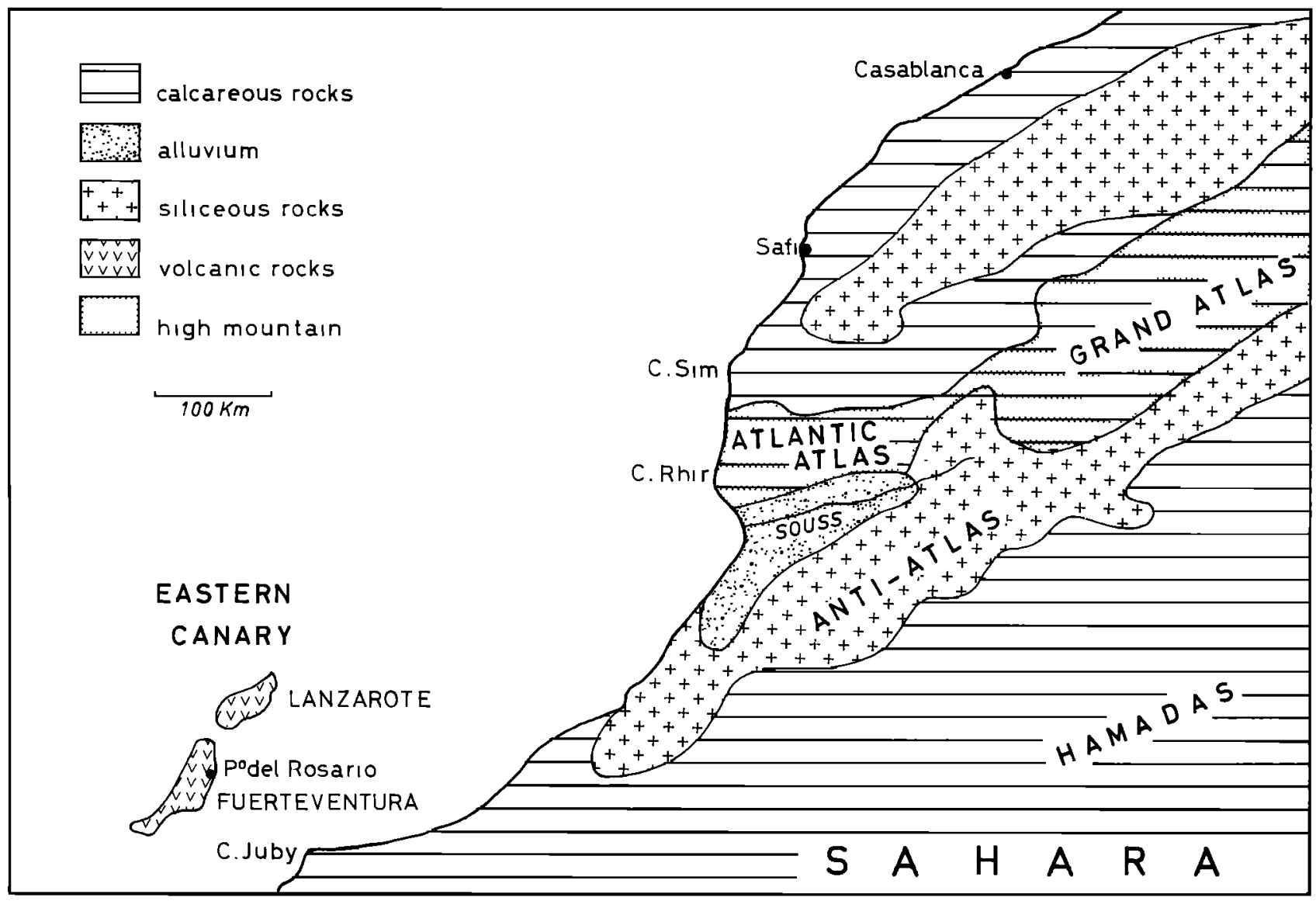

Fig. 1. Localization map with lithological data.

logy of particles collected on Fuerteventura Island allowed us to separate the sampling period into three phases. Two of these correspond to contributions of mineral dust from African arid areas. These are separated by an interval with low mineral concentrations which is characteristic of a mean oceanic situation. Among the periods, corresponding to inputs of African dust, the first results from an outbreak coming from the coastal Moroccan Atlantic Atlas. The dust cloud was thick but very settled by a long travel over the Atlantic Ocean. The second is more bound to an air mass loaded with particles from Moroccan and Algero-Moroccan regions, without a dust outbreak event.

\section{Sampling and Analytical Procedures}

The aerosol sampling was performed in a little harbor called Puerto del Rosario (Figure 1). The apparatus consisted of a five-stage cascade impactor EGAI 80 [Bergametti et al., 1983] and was put on a $20-m-h i g h$ building. A nominal flow rate of $1 \mathrm{~m}^{3} \mathrm{~h}^{-1}$ was used during the sampling period, which had a duration of 12 hours. No rains occurred during the sampling.

For this airflow the nominal size cutoffs (D50) are about $7,3.5,2,1.25$, and $0.5 \mu \mathrm{m}$ for stages 1 to 5 , respectively. Particles smaller than $0.5 \mu \mathrm{m}$ were sampled on a final filter; the largest $(>7 \mu \mathrm{m})$ were collected qualitatively by washing the wall of the first stage with alcohol at every change of filters (at 0800 and $2000 \mathrm{UT}$ ).
Nuclepore $0.4-\mu \mathrm{m}$ filters have been used for impaction supports and final filtration.

The collected samples have been successively analyzed by $X$ ray fluorescence, $X$ ray diffraction (XRD), and by scanning electron microscopy (SEM). This order had been chosen on account of the more and more destructive effects of each manipulation.

Flemental analyses ( $\mathrm{Al}, \mathrm{Si}, \mathrm{Fe}, \mathrm{Ca}, \mathrm{T} 1, \mathrm{P}$ ) have been performed by wavelength dispersive $X$ ray fluorescence spectrometry (Compagnie Générale de Radiologie $\alpha 10$ ), according to the method described by Elichegaray et al. [1981]. The sample was placed in an irradiation chamber and the excitation is produced by a $X$ ray tube with a $\mathrm{Cr}$ target. The sample was counted two times for at least $50 \mathrm{~s}$ on a proportional gaseous flux detector, using the $\mathrm{K} \alpha$ ray of each element. Total countings were corrected for blank filter countings. Analytical precision is better than $7 \%$ for every analyzed element.

Mineral components were identified using $X$ ray diffraction. Filters were lightly loaded, and it was not possible to recover the grains either by scraping the filter or by chemical dissolution of the polycarbonate filter for carrying out a powder diffraction. The $X$ ray diffraction was made directly on the filter by setting the point of impact of the dust particles in the center of a vertical goniometer (Philips diffractometer $P W$ 1130, using Fe -filtered Co $K \alpha$ ). Some filters were not perfectly flat, and it was necessary to support the paper with a glass fastened under 


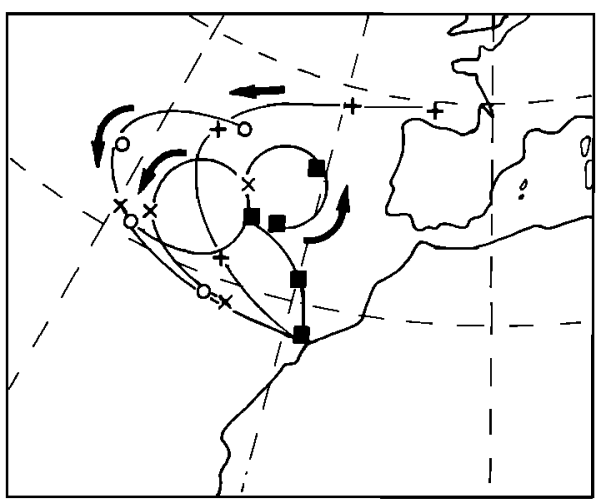

$\times 8 / 4$ to $12 / 4 \quad 12$ h GMT

- $9 / 4$ to $13 / 4$

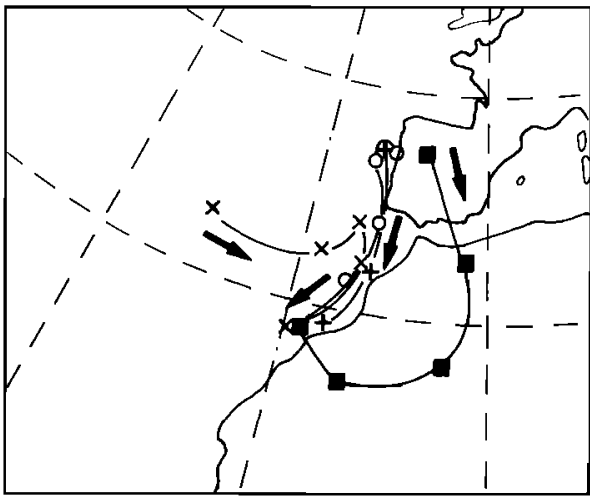

$\times 12 / 4$ to $16 / 412 \mathrm{~h} \mathrm{GMT}$

o $13 / 4$ to $17 / 4$

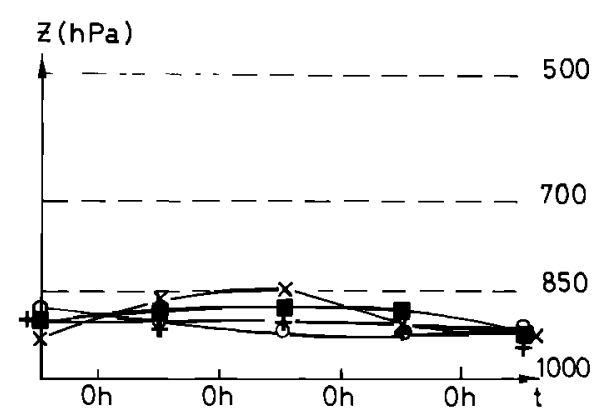

$+10 / 4$ to $14 / 4$

- $11 / 4$ to $15 / 4$

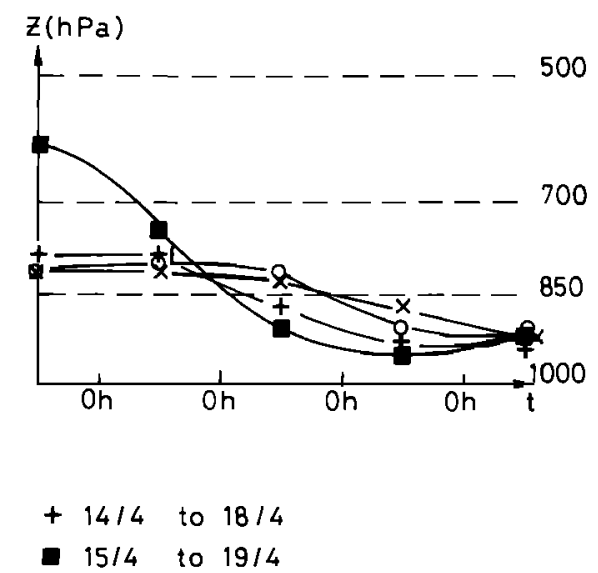

Fig. 2. Trajectories arriving on Fuerteventura at $925 \mathrm{hPa}$ from April 12 to $19,1984$. (Left) Horizontal projection. (Right) Vertical section.

the filter. The $X$ ray record of an unexposed filter shows a strong line between 4.5 and $5.7 \AA$ and reaches a maximum at $5.10 \AA$. This area was consequently unusable.

On the whole, XRD traces were correct, with some minerals giving narrow peaks (for instance, halite, calcite, gypsum). However, small peaks were difficult to measure, and we had some problems trying to determine some constituents, particularly zeolites, which have three sinall peaks at $8.1,4.07$ and $3.18 \AA$.

Another problem affects the significance of missing peaks when the filters are very lightly loaded. In this case the nondetection of a major mineral might be due to the small amount of matter collected on the filter with respect to the detection threshold of this mineral, rather than a total absence of it in the aerosol. This is the case, for example, of the sample collected during the day of April 14, which corresponds to the lowest air volume sampled over the whole period, and for which the determination of calcite is not possible.

\section{Trajectory Analysis}

Several trajectories were computed for the sampling period, using the wind analyses pro- cessed four times a day by the ECMWF (European Center for Medium-Range Weather Forecasting). The software allows us to compute trajectories for any starting or ending point at any time. The vertical level is specified for the initial point, and the trajectories are computed taking account of the vertical velocity values given by the ECMWF [Martin et al., 1984].

Seven trajectories arriving on Fuerteventura at $925 \mathrm{hPa}$ are reported in Figure 2. The arrival dates are each day between April 12 and 19 at 1200 UT. The trajectories' duration is 96 hours. The $925-\mathrm{hPa}$ level is selected for this first investigation because it is intermediate between the lowest levels avallable on the ECMWF data base.

At this stage, two periods seem to be well defined: one from April 12 to 16, of quasi-exclusive oceanic influence, and another from April 17 to 19 , with a possible continental origin.

The Drift of Dust on April 6

The satellite images (Figures 3 and 4 ) show a dust cloud originating over the Sahara at about 9000 UT on April 6 and moving towards the Canary Islands until 1600 UT. Meteorological measurements indicate that the surface wind velocity at 


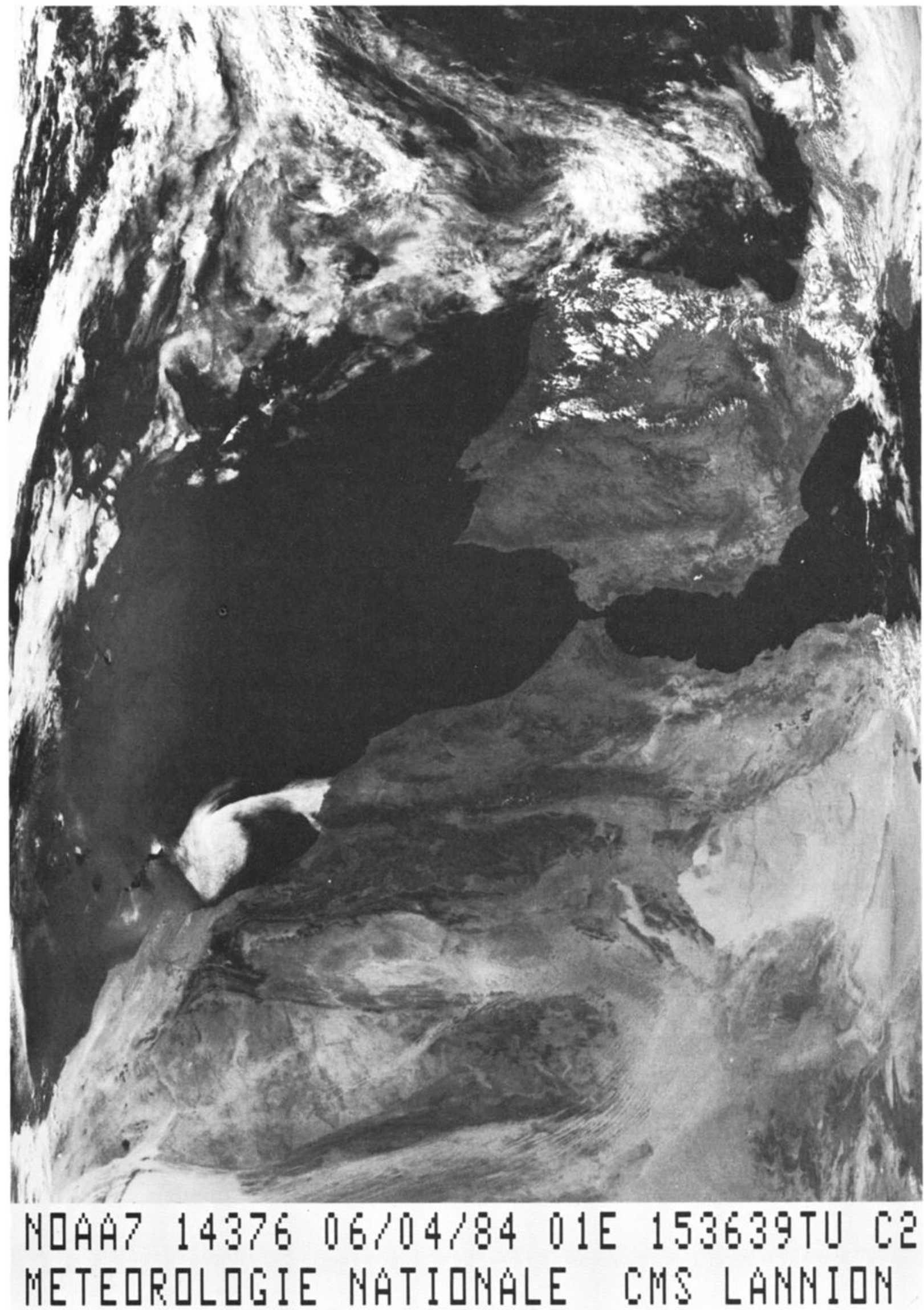

F1g. 3a. NOAA 7 image, April 6, 1984, 1536 UT. Channel $2(0.725-1 \mu \mathrm{m})$. 


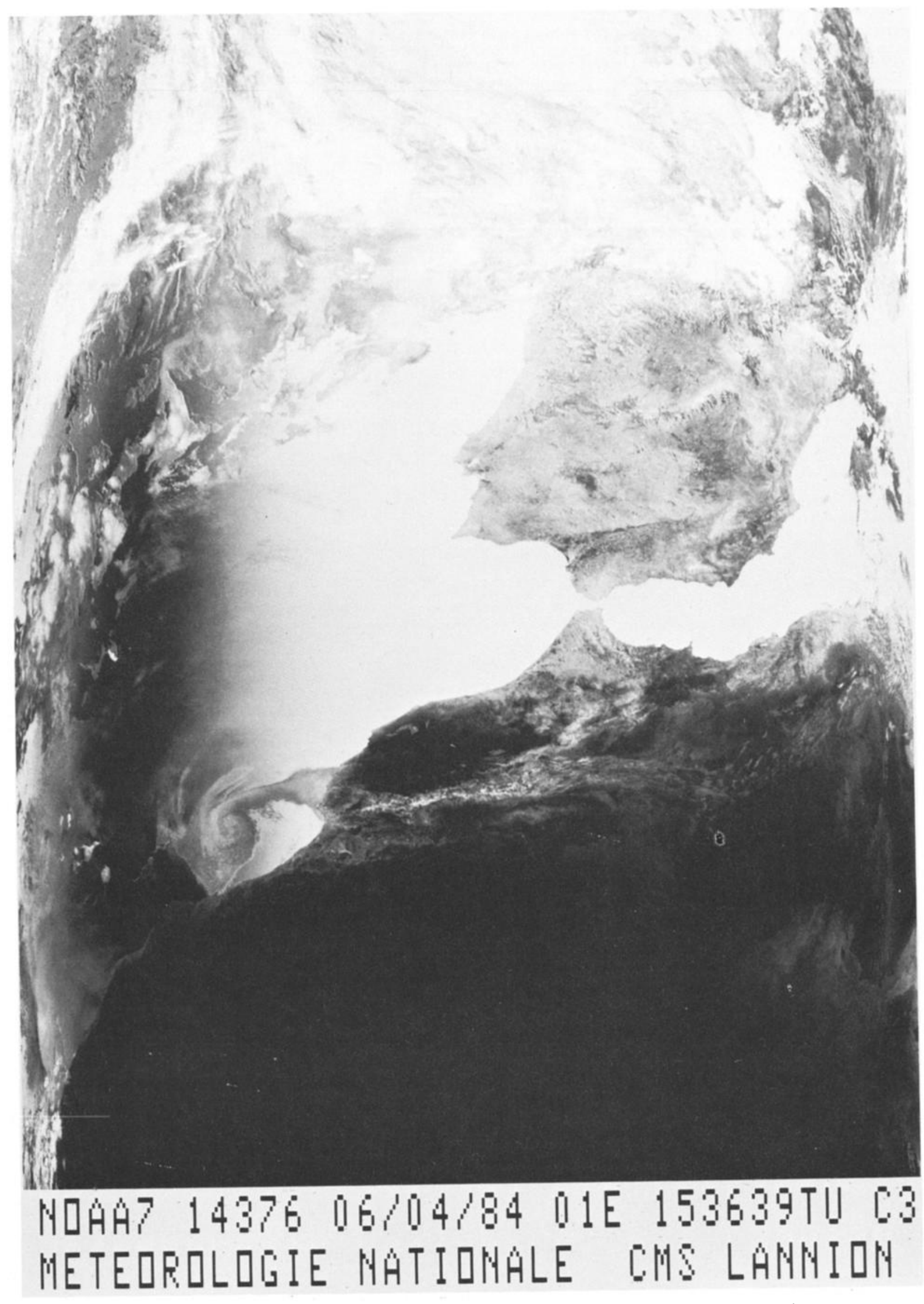

Fig. 3b. NOAA 7 image, April 6, 1984, 1536 UT. Channel $3(3.55-3.93 \mu \mathrm{m})$. 


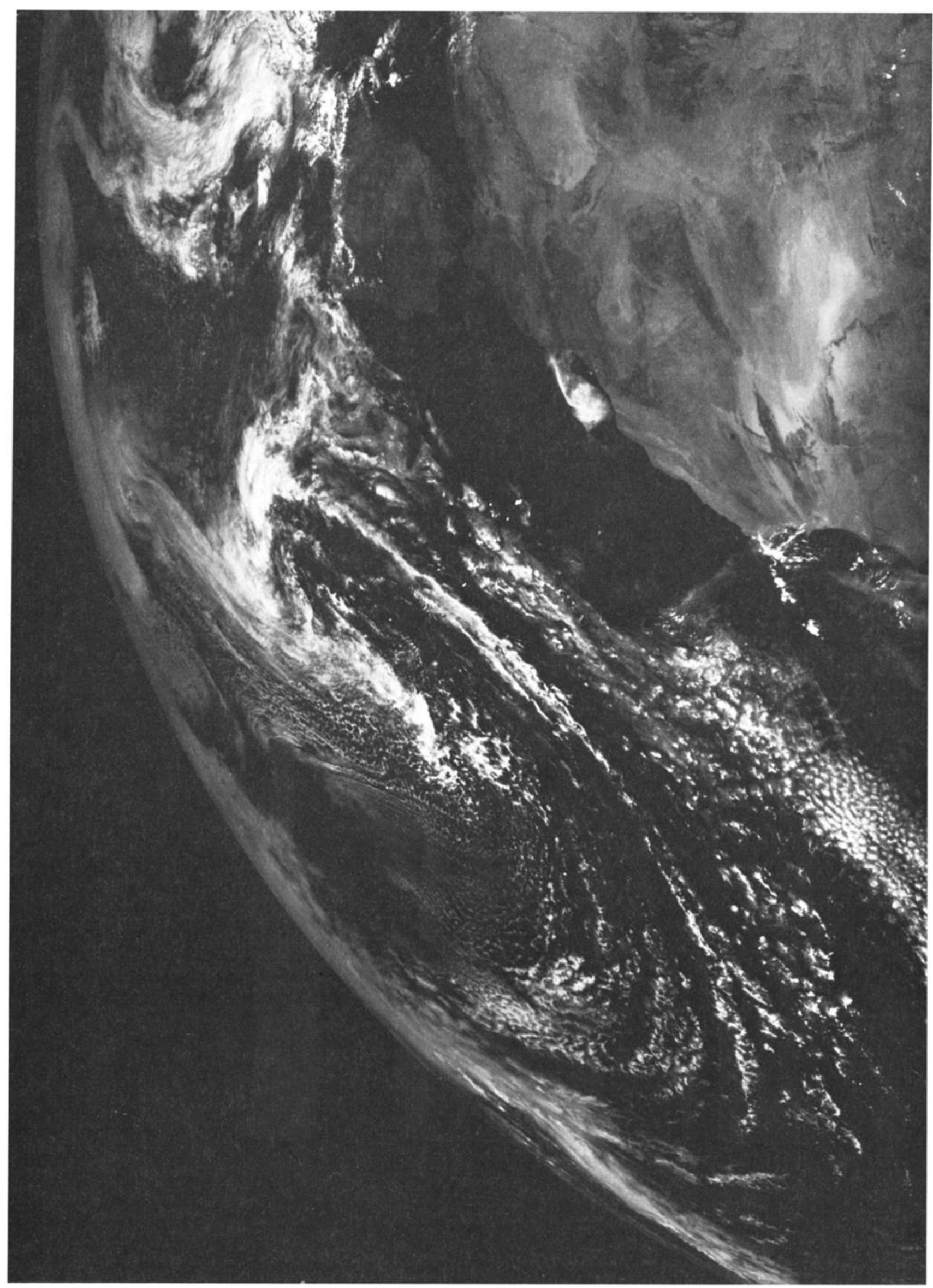




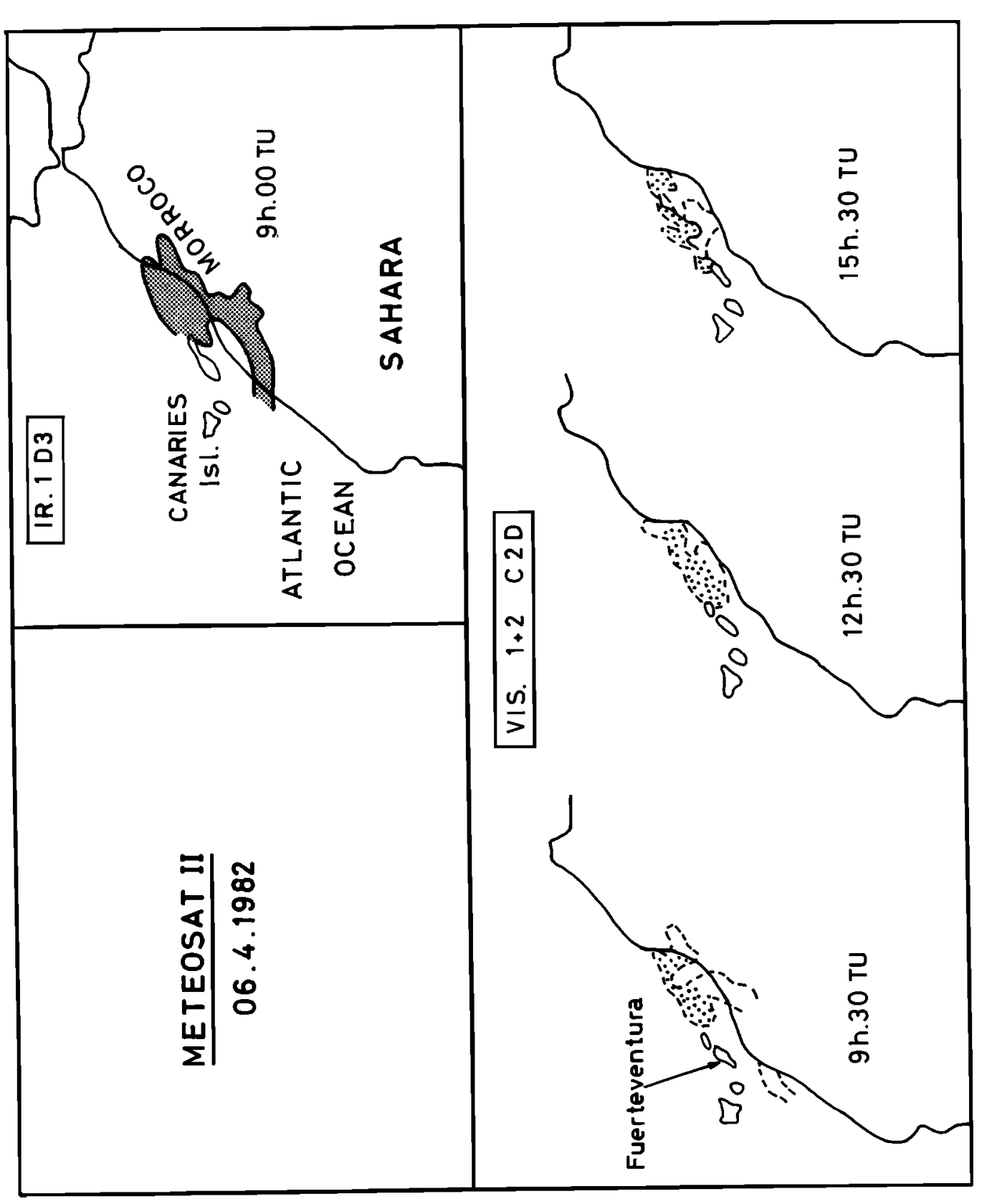

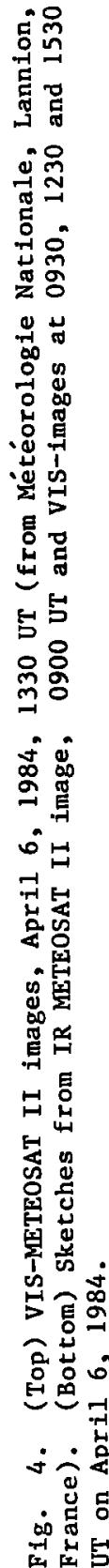




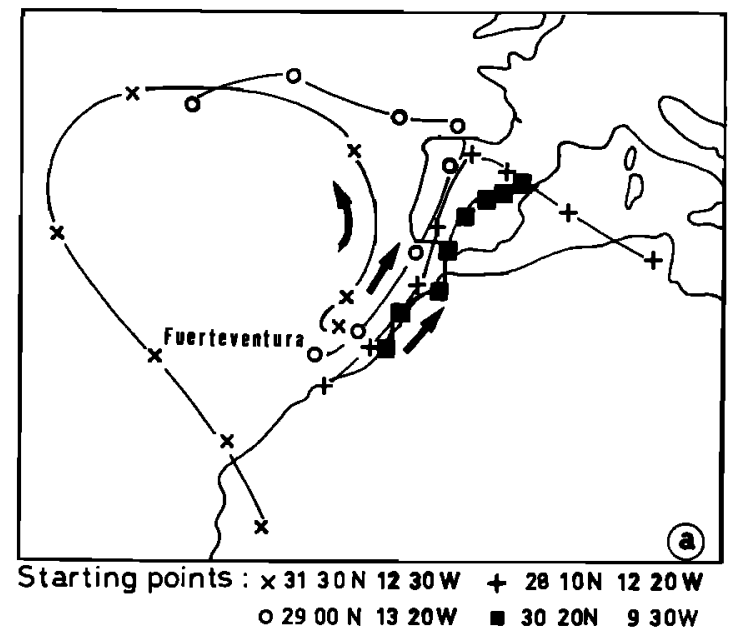

$Z(\mathrm{hPa})$

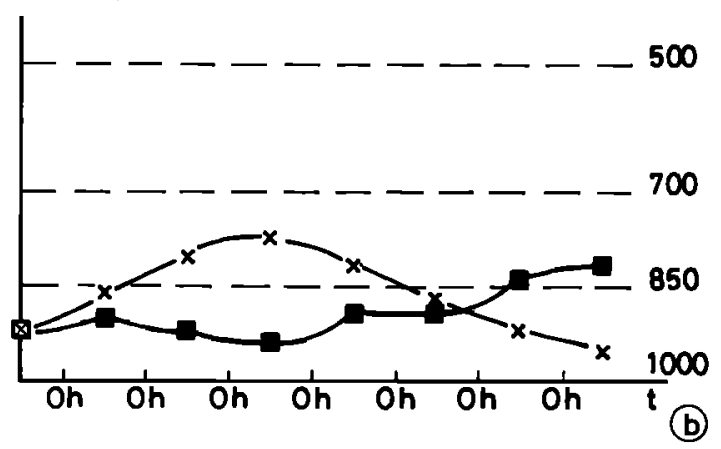

Fig. 5. Four forward trajectorles from April 6, 1200 UT to April 13, 1200 UT, starting from the dust cloud boundaries as determined by satellite (one plot every 24 hours). (a) Horizontal projection. (b) Vertical section.

0000 UT was $20 \mathrm{~m} \mathrm{~s}^{-1}$ (easter1y); at the 700-hPa level, the wind is westerly.

The NOAA 71536 UT images show a well-developed vortex, the diameter being about $150 \mathrm{~km}$. The METEOSAT images show the genesis of the dust cloud between Cape S1m and Cape RhIr at 0930, and its motion towards Lanzarote and Fuerteventura islands at 1530 . The vortex is probably born in a stable air mass, in front of a very unstable cold-air inflow. This cold front stands at a distance about $400 \mathrm{~km}$ away from the Canary Islands unt11 April 8, then vanishes. In a similar case of February 1982, described previously [01iva et a1., 1983], there was no warm airstream toward the NE along the front. Thus the vortex was probably generated locally, i.e., by thermal (sea-land temperature gradient) and/or dynamical (due to the Atlas area orography) processes.

After $1530 \mathrm{UT}$, the evolution of the cloud can no longer be determined by the satellite images, and a simulated trajectory analysis is needed. This analysis is reported in Figure 5. We compute four forward trajectories during 7 days, from April 6 at 1200 UT to April 13 at 1200 UT. The starting points are selected as the limits of the cloud seen by the satellite. The motion during the first 12 hours is almost zero, then the cloud appears in a southerly stream after about 36 hours with little difference. Then, a spectacular difference occurs, with one part of the cloud mo- ving eastward and the other westward. Finally, one trajectory comes back to the Canaries area, after a 6-day transportation over the ocean. It is important to notice that this trajectory was going upward during the first 60 hours, until the 750-hPa level. We obtain a similar frame by computing trajectories beginning at 1800 UT. Consequent1y, this dust is probably sub-Saharan layer dust, and it seems to originate below the main maritime air near its base. Thus it is possible to explain highly divergent trajectories and the mixed air mass character.

\section{The Last Period}

The April 17, 18, and 19 trajectories of Figure 2 are computed in view of arriving exactly on Fuerteventura; we also determined (Figure 6) four trajectories arriving at about $170 \mathrm{~km}$ away from Fuerteventura, to the north, east, south, and west, on April $18(170 \mathrm{~km}$ is chosen because it is the typical dimension of a Gaussian puff at the one standard deviation concentration level after a 4-day transport). We can see that a noticeable part of the air mass components over Fuerteventura is unquestionably of Algerian and Moroccan Sahara origin.

In summary, one can make out three periods during the sampling experiment: (1) from 12 to 14 April the Canary Islands are under direct oceanic influence, but they are also in the deposition area of a dust cloud which originated on April 6 over the African continent (phase A); (2) on April 15 and 16, oceanic Influence only (phase B); (3) April 17, 18, and 19, matching of continental and oceanic origins (phase C).

\section{Elemental and Mineral Analyses: Filter by Filter}

The concentrations of elements in aerosol samples obtained by summing up all sizes for each sample are plotted in Figure 7. If a similar varlation for all elements can be observed during

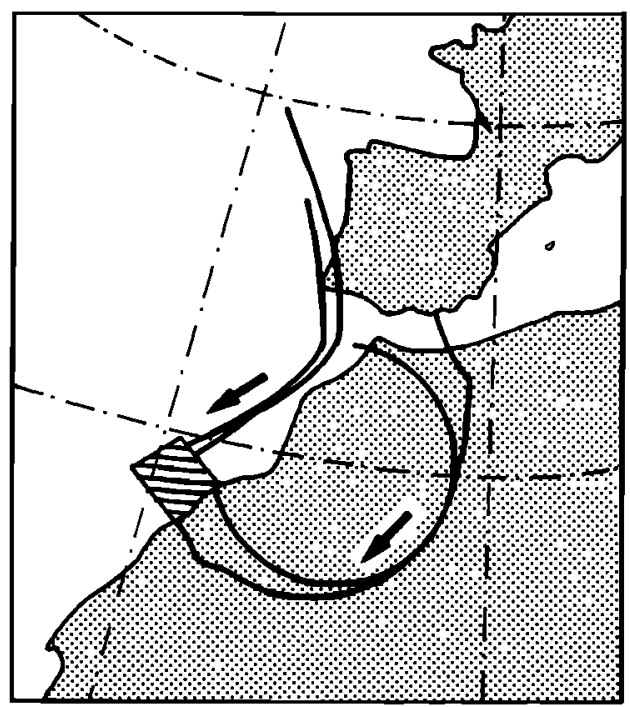

Fig. 6. Frame of the four backward trajectories arriving at $170 \mathrm{~km}$ away from Fuerteventura on April 18, 1800 UT (starting on April 14 at 1800 UT). 

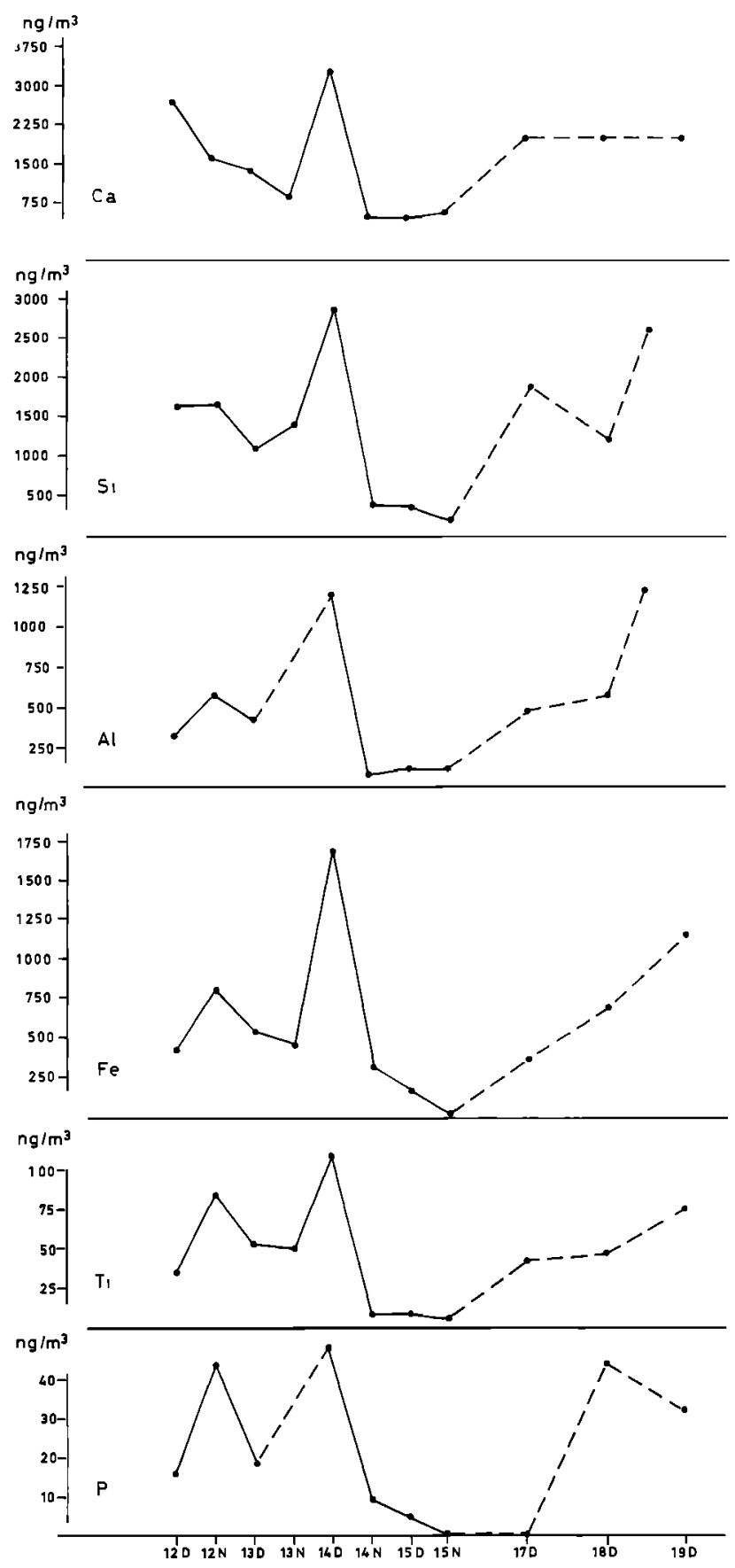

Fig. 7. (Opposite) Variation of the elemental composition during the sampling period. (D, sampling from 0800 to $2000 \mathrm{UT}$; N, sampling from 2000 to 0800 UT.)

the sampling period, their concentration range is relatively large (more than 1 order of magnitude). Thus the concentrations of $S I$ and $A l$ ranged from 210 to $2900 \mathrm{ng} \mathrm{m}^{-3}$ and from 85 to 1210 $\mathrm{ng} \mathrm{m}^{-3}$, respectively.

The highest values are significantly greater than the mean ones for the marine atmosphere: in the North Atlantic, Duce et al. [1975] observed a concentration range for aluminium between 8 and $370 \mathrm{ng} \mathrm{m} \mathrm{m}^{-3}$ and Buat-Ménard and Chesselet [1979] obtained a mean value of $160 \mathrm{ng} \mathrm{m}^{-3}$ of Al in the tropical North Atlantic marine atmosphere. On the other hand, our highest values are comparable to atmospheric concentrations obtained over the North Atlantic Ocean and the Mediterranean Sea during transport of mineral material from North African arid regions [Chester et al., 1972; Prospero and Carlson, 1972; Prospero, 1979 (for Atlantic Ocean); Chester et al., 1984; Dulac, 1986; G. Bergamett1 (unpublished results, 1986) (for Mediterranean Sea)].

Figure 8 illustrates the temporal variation of $\mathrm{Ca} / \mathrm{Si}$ ratios. These are very high (in most cases larger than 1 , i.e., a predominance of Ca concentrations versus $\mathrm{Si}$ ones). These values are greater than those obtained from abundances of the elements in the principal types of sedimentary rocks (between 0.08 and 0.10 ) and igneous basaltic rocks $(0.131)$. Only carbonated rocks show $\mathrm{Ca} / \mathrm{Si}$ ratios greater than $1(12.6)$ (data from Turekian [1971]).

On the other hand, we observe that the $\mathrm{Ca} / \mathrm{Si}$ ratio values are opposite to those of $\mathrm{Ca}$ and $\mathrm{Si}$ concentrations. The high values of $\mathrm{Ca} / \mathrm{Si}$ during the low-concentration period ( $B)$, suggest a possible and significant marine contribution for $\mathrm{Ca}$ during this time.

However, the similar profile of variation for $\mathrm{Ca}$ and crustal elements ( $\mathrm{Al}, \mathrm{Fe}, \mathrm{Si}$ ) during the high-concentration periods ( $A$ and $C$ ) Indicates a major crustal component for $\mathrm{Ca}$ at that time. Thus the $\mathrm{Ca} / \mathrm{SI}$ ratios (which are between 1 and 2) in these two continental periods could be associated with a source region.

Mineral compounds identified by X ray diffraction are classified into three groups: (1) minerals which appear only occasionally, i.e., palygorskite, mica, and augite (Figure 9); (2) major minerals (Figure 10) (A number code from 0 to 4 is given to each mineral according to intensity XRD line. For each sample, this value is relative to the sampled volume.); (3) minerals noted by "occurrence" or "lack" ( 1 or 0 code), $1 . e .$, zeolites, pyrolusite, and gypsum.

Some of these minerals are present all during the sampling in low amounts: zeolite and pyrolusite are typical of volcanic rocks, and their occurrence is probably indicative of local contribution. Gypsum appears in impactor stages 2, 3 , and 4 and may originate in part from the mari-

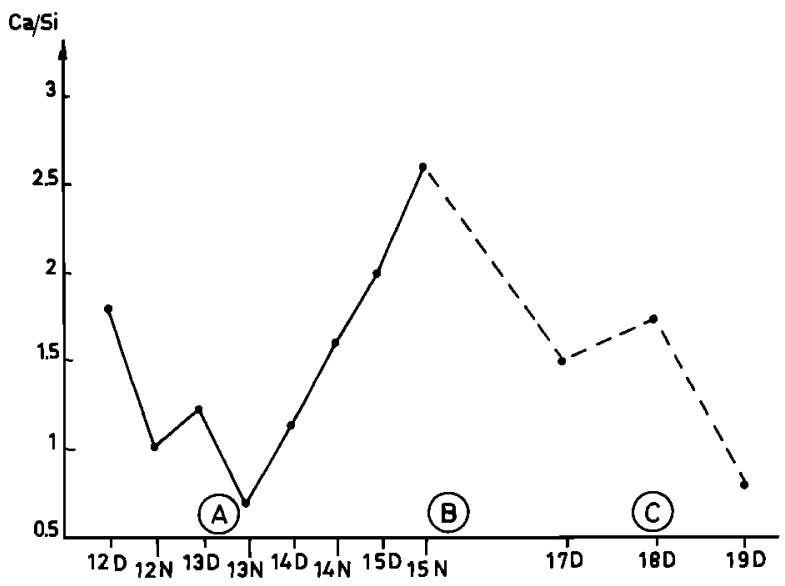

Fig. 8. Variation of the $\mathrm{Ca} / \mathrm{S} i$ ratios. (D, sampling from 0800 to 2000 UT; N, sampling from 2000 to 0800 UT.) 


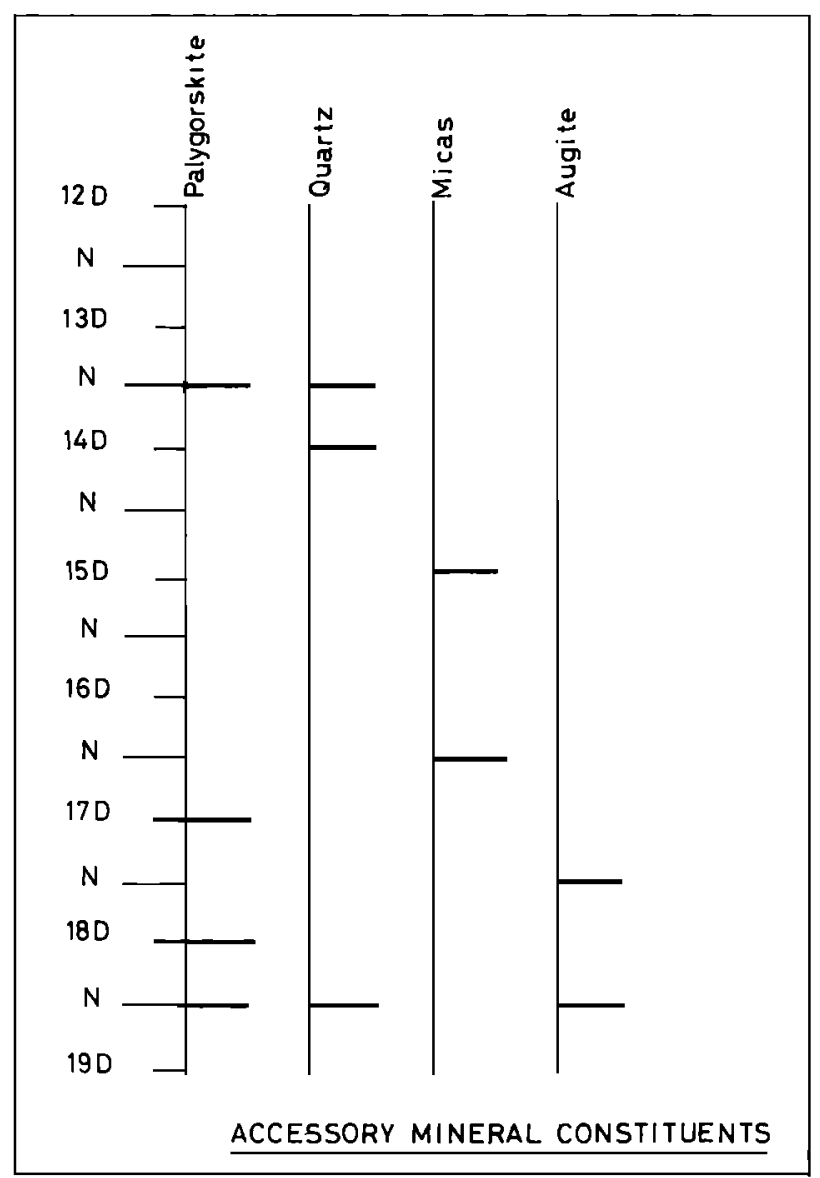

Fig. 9. Episodic mineral constituents of aerosols during the sampling period.

ne source, as indicated by the presence of hallte, which is found in all filters (except the finest particles). These four minerals form a kind of "background" and therefore are not useful for the identification of the source region of the transported dust.

On the other hand, considering elemental concentration levels and "episodic" mineral compounds, it is possible to distingulsh three successive periods:

1. During the first phase (A) from April 12 to the night of April 14, Si concentrations were always higher than $1 \mu \mathrm{g} \mathrm{m}-3$ and $A 1$ concentrations were higher than $0.3 \mu \mathrm{g} \mathrm{m} \mathrm{m}^{-3}$, with a significant major peak during the day of April 14. Figure 11 shows the variation of Al/S1 ratios for the different stages of the cascade 1mpactor over the sampling period. This ratio changes with particle size. Thus for this first phase the finest particles (corresponding to the backup filter of the cascade impactor, i.e., particle diameter less than $0.5 \mu \mathrm{m}$ ) have an $\mathrm{Al} / \mathrm{Si}$ ratio significantly lower than that of mean aerosol, or even of mean soil. Thls indicates the occurrence of a component of fine Si particles which are not, for their major part, associated with Al. The same result obtained for the $\mathrm{Fe} / \mathrm{S} 1$ ratio allows us to assume that this granulometric range is essentially dominated by fine quartz particles, which have been observed by SEM examination. Figure 12, which represents the contribution of fine parti- cles to the total concentration of $\mathrm{Si}_{\text {, shows that }}$ the fine component is significant only during the first mineral period $(A)$ and could be more than $40 \%$ of the total collected mass of Si. At the same time, $X$ ray diffraction shows that only palygorskite is associated with quartz. Their simultaneous occurrence suggests an allogenous origin, which is confirmed by aeolian traces observed on these grains by SEM (Figure 13).

2. The low elemental concentration period (B) from April 14 to the day of April 16, shows concentrations of $S i$ and $A l$ which are very stable and fall to 0.21 and $0.085 \mu \mathrm{g} \mathrm{m}^{-3}$, respectively. These lower values are comparable to Atlantic atmospheric "background." During this period the $\mathrm{Al} / \mathrm{S} 1$ ratios become greater $(>0.47)$ than that of the mean aerosol and are in the range of A1/S1 ratios for clay minerals. This result agrees with the lack of allogenous minerals (palygorskite, quartz), which were present during the preceding phase, and by the abundance of mica (whose accurate determination was hindered by the peak of the filter). The SEM examination shows the preponderance of biotite in micas.

3. The last phase (C) corresponds to the second intensive mineral period, from April 17 to the end of the sampling period. The elemental concentrations are close to those obtained during the first period. Size-differentiated Al/S1 ratios do not differ significantly from the mean range for aerosols. Nevertheless, the $C$ period differentiates itself from phase $A$ by the presence of augite from April 17 to 19 (whereas it is not observed during outbreak phase A) and also by a greater amount of calcite during the end of sampling.

From April 17, among the other major species, the XRD patterns show new, well-defined, and sometimes strong, peaks. These are present on all recordings of the end of sampling. Occurrence of ammonium sulfate has been confirmed by SEM. A line at $3.88 \AA$ might be assigned to sulfur. These minerals are regarded as anthropogenic. It is difficult to attribute an accurate origin to the other minerals.

In conclusion, elemental and mineral analyses allow us to corroborate the meteorological study with regard to the origin of the sampled air masses. In addition, the occurrence of a characteristic mineral in each of the two mineral periods ( $A$ and $C$ ) and the variability of the $A 1 / S 1$ ratios allow us to emphasize the different nature of the sources contributing to each mineral event. Concerning these two mineral episodes, we try to display a specifically allogenous character of these dusts with the help of the analysis of the elementary particles by SEM and energy dispersive $X$ ray analyzer (EDXA).

\section{SEM and EDXA Examinations: Particle by Particule}

Only the two periods of African contributions are of concern for the SEM and EDXA analyses. The characterization of particle shape, surface features, and mineralogy was emphasized by this grain-by-grain examination. It allows us to determine: (1) the processes resulting from aeol1zation since the liberation from the source substrata; (2) the mineralogy of particles, in order to define their possible allogeny when 


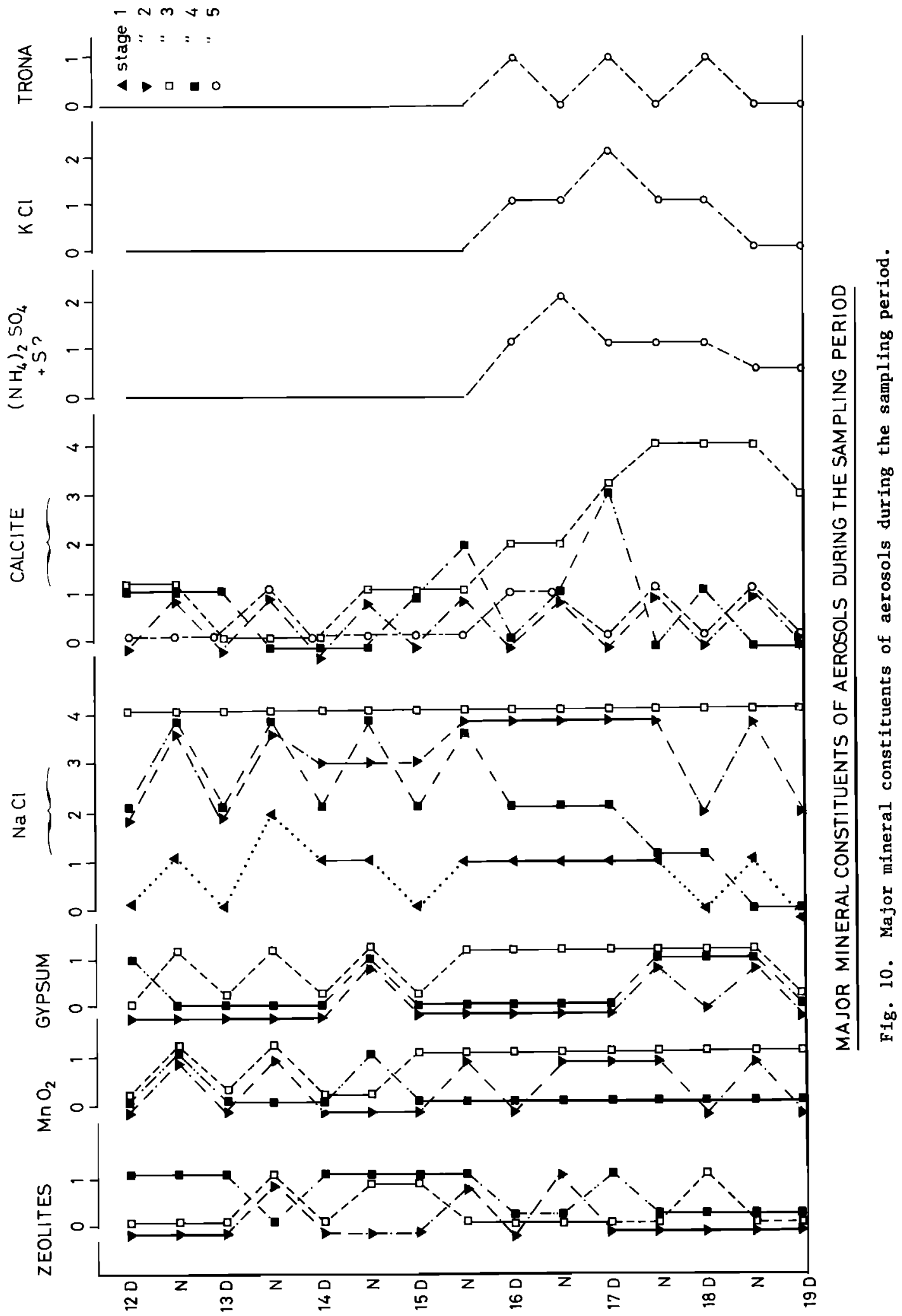




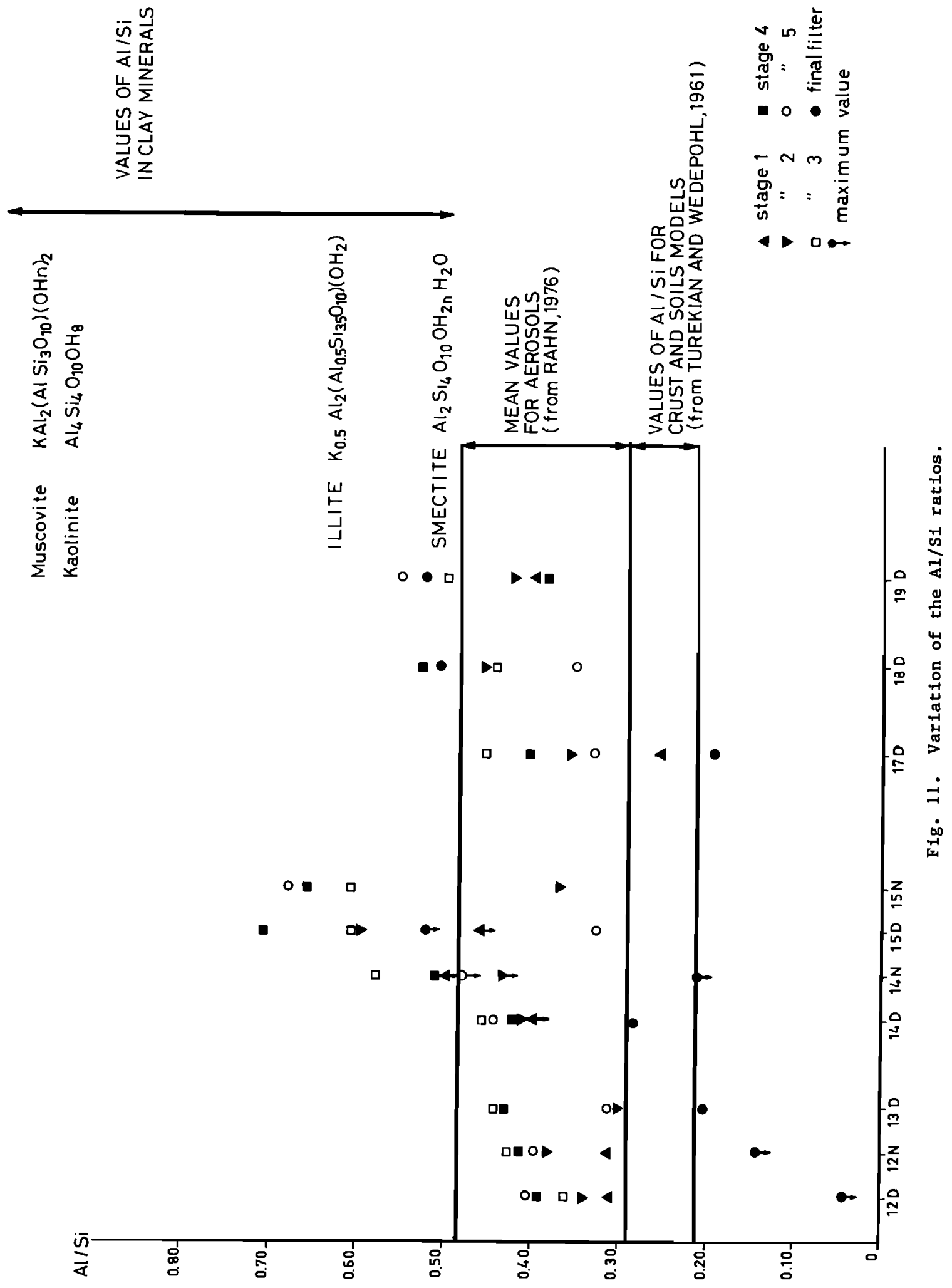




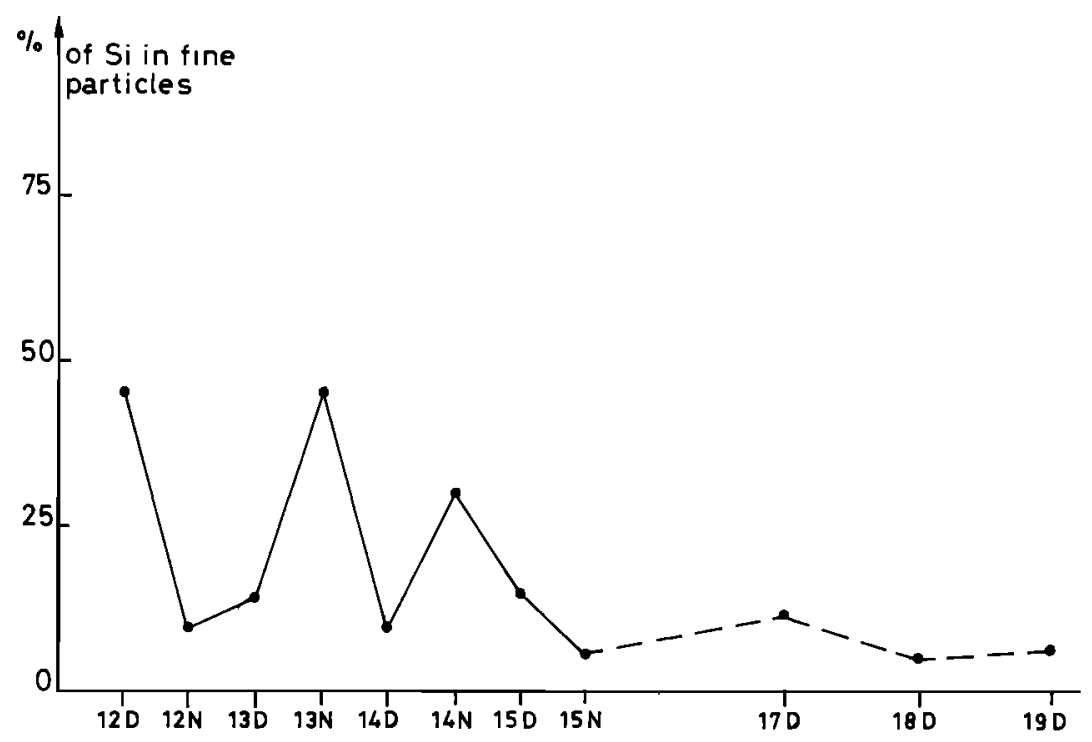

Fig. 12. Contribution of fine Si particles to total concentration.

there is a chemical characterization by EDXA with SEM examination.

A particle is allogenous when its mineralogy is different from that of the local substratum. Our first aim is to display significant markers of African and desert area origin for these dusts, without relation to the island volcanic substratum. In this one-by-one particle analysis, our examination concerns, on the one hand, the finest sizes deposited on the different filters and, on the other hand, the coarser grains directly sampled on the pump inlet funnel by alcohol washing and filtration. These gold-plated samples were examined by Jeol JSM 2 SEM with energy dispersive system (EDS-Ortec).

Mineralogical Constituents of Each Particle Size

Finest particles. The size of these particles is between 0.5 and $10 \mu \mathrm{m}$, mainly between 2 and 5 $\mu \mathrm{m}$. Three types of shape are seen: (1) shapes where mineral crystalline structures are always occurring, for example, spindles of weathered micritic (Figure 14-3), geometrical albite particles, Ca carbonate grains (Figure 14-5), Al-Ca carbonate grains (Figure 14-6), and silica (Figure 14-4) or hematite (Figure 14-9); (2) fluffy chain aggregates with unknown mineralogical composition, 1.e., carbonated mixing, mixings of carbonates and silica in the same proportions, and alumino-silicated grains with $\mathrm{K}$ and $\mathrm{Fe}$; (3) any form particles, 1.e., alumino-silicated mixings with $\mathrm{K}$ and $\mathrm{Fe}$ of rounded shapes, irregular particles of varied carbonates, micaceous clays, and quartz.

Coarse grains. These, sometimes, exceed 100 $\mu \mathrm{m}$, but they are mainly between 20 and $80 \mu \mathrm{m}$. Generally speaking, the particles have a smooth and of ten rounded shape, with a few exceptions such as some angular quartz (Figure 13-2) and mica flakes.

In the rounded shape components, Ca carbonate and phosphate, iron oxide, and altered $\mathrm{K}$ feldspar grains occur. There are also vegetal fragments, microcodium particles, and spores.
At these sizes, most of the quartz grains have a subrounded or rounded form (Figure 13-1), and their previous morphoscopical examination has often shown their stained and reddened characters (Figure 13-5). Moreover, the SEM examination indicates that on such grains there is a thicker surficial silica film and a frequent coating by crushed palygorskite fibers, more or less spread on the surface or trapped in quartz caries ( $F$ igure 13-6). Finally, rounded grains entirely composed of palygorskite are noticeable in the dusts (Figure 13-8).

Micromorphological interpretation. On one hand, the shapes of the finest particles show a micromorphology of dust 1mmediately loaded in suspension by wind and without any trace of mechanical processes related to initial rolling and saltation. The irregular particles of varied form can come from sand or rock blasting. Fluffy chain aggregates are very common in aerosols [Julien et al., 1985].

On the other hand, the shapes of the coarse components are Indicative of the previous shaping and loading aeolian processes. For example, the mica chips have upturned and crushed edges (Figure 13-7) related to mechanical impacts during their mobilization and transport by wind. The rounded quartz grains' characteristics are also Inherited from their previous desert "history," before their aeolian exportation to the Canary Islands. Their stained and reddened aspects are often used to describe Saharan sandy particles. In other respects the silica film on such grains has a well-known explanation, the surficial amorphization of quartz by mechanical actions during the early grain saltation [Le Ribault, 1977]. Moreover, during these initial aeolian processes, fibers of palygorskite, which is a very common clay in the limestone plateaus of the northern Sahara, were loaded on the quartz grains and altered by impacts. Thus the occurrence of rounded palygorskite particles is also a very good indication for the desert orfigin of the dust. Indeed, such grains are wind-shaped from varied clayey substrata of Sahara and exported beyond the desert margins [Coudé-Gaussen and Blanc, 1985]. 

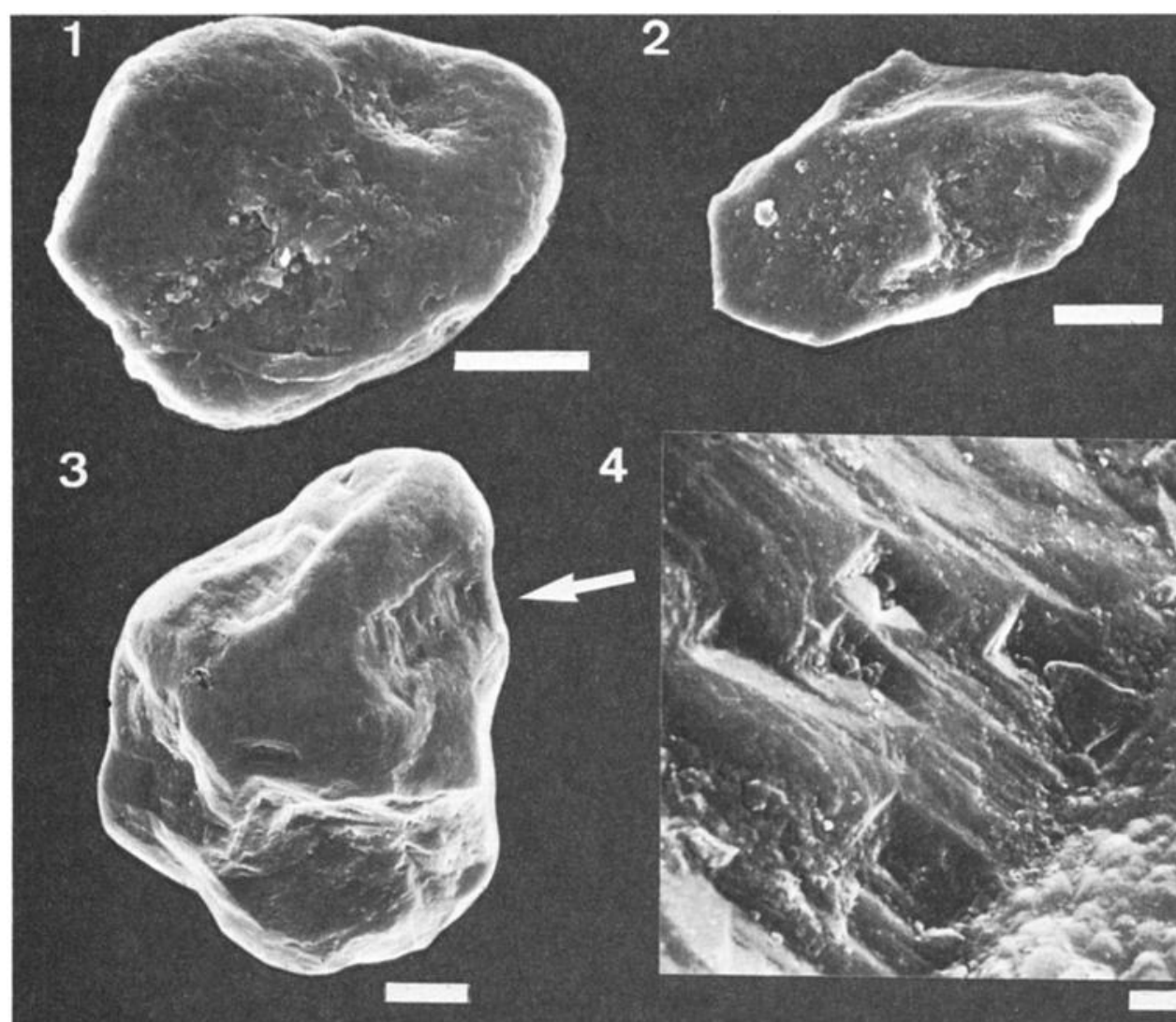

4
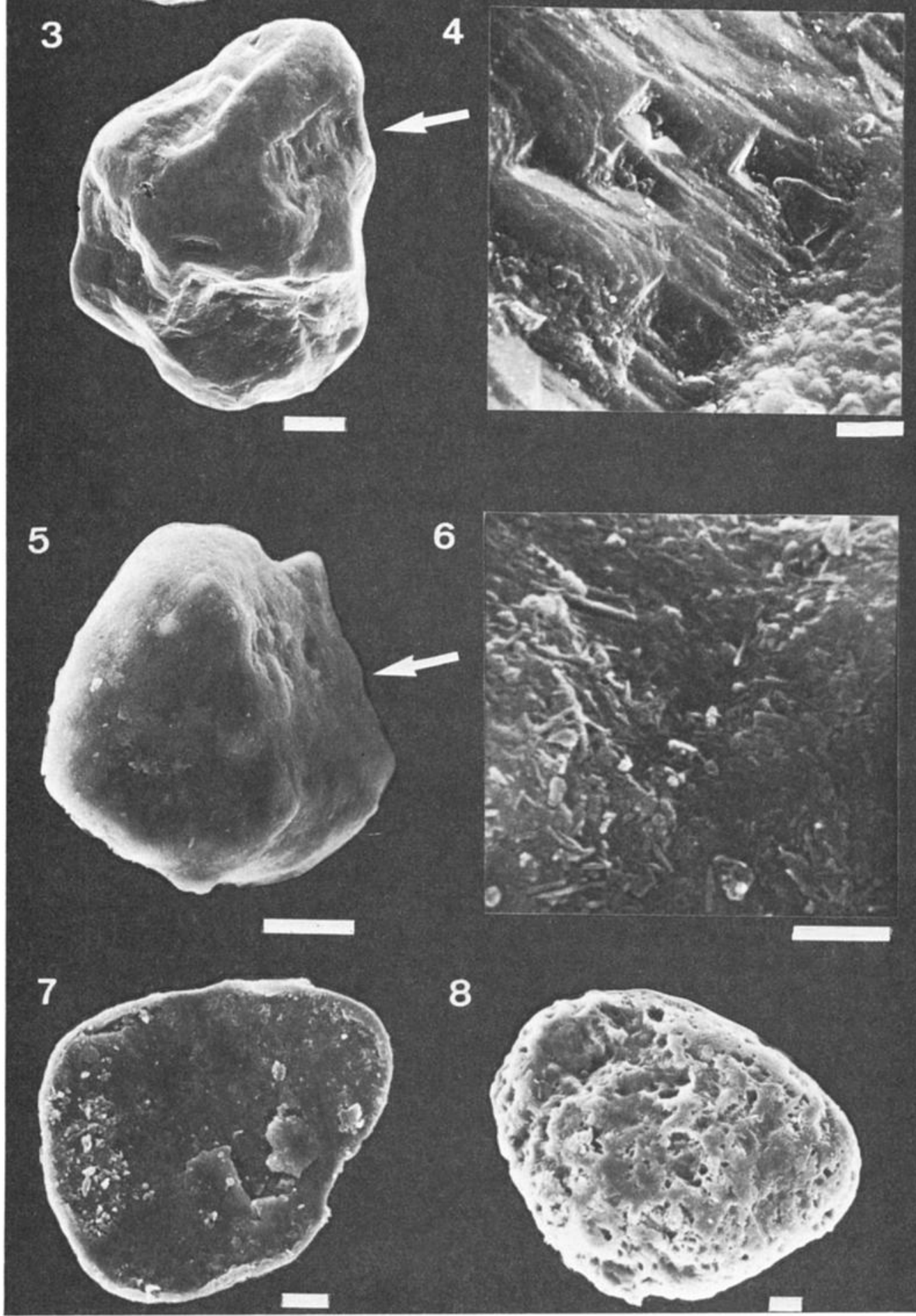

8

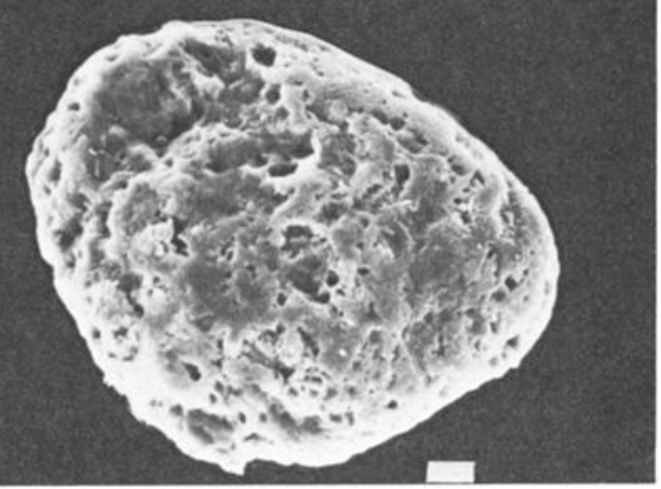


Finally, the micromorphology of the coarser components of the dusts seems more indicative of the previous aeolian desert shaping than that of the finest particles, which were subjected less to initial mechantcal processes during their mobilization.

\section{Markers of African Origin}

Some of the examined particles have a local or marine origin (for example, $\mathrm{NaCl}$ ). Others are unquestionably allogenous with regard to the 1sland volcanic substratum, for example, the quartz observed in the finest particles as well as in coarser grains. Thus mica particles probably have the same significance. In addition, the allogenous character of the mineralogical quartz-mica assemblage is reinforced by the same size and the frequent aeolization of their particles.

In all these observed samples the mineralogical assemblage looks like those of other well-known Saharan dusts [Coudé-Gaussen, 1981; Whalley and Smith, 1981; Tobias and Megie, 1981; MacTalnsh and Walker, 1982; Wilke et al., 1984]. As in those dusts, the Canarian dusts show, beside a lot of quartz grains, feldspars, micas, gypsum, palygorskite, and abundant $\mathrm{Ca}$ carbonates.

Concerning micromorphological criterla, the main evidences concern the coarse grains because marks of aeolization are better impressed. The shape of the collected particles issues from their inftial wind moulding: they are "worked" and often rounded; that is the case for many quartz, $\mathrm{Ca}$ carbonates, palygorskite, or feldspar grains. In the grain surface, numerous microfeatures result from impacts during mobilization and transport phases; some quartz is covered by an amorphous silica film or by a St-Fe coating, both of which are common surficial features on desert reddened quartz.

Obviously, if the presence of only one of these criteria for a collected particle can be taken as unquestionable proof of desert and Afr1can origin (it is only indisputable for quartz), occurrence of many of them on this particle seems to be a very good indication of such an origin. Thus the aeolized micromorphological character for mica chips or palygorskite grains suggests their allogeny and African source.

\section{Discussion}

\section{The Occurrence of Coarse Particles}

Our observations show the existence of particles whose diameter can be greater than $100 \mu \mathrm{m}$

Fig. 13. (Opposite) Tracer Minerals. Graphic scale is $20 \mu \mathrm{m}$, except for micrograph 4 and 6 , where scale is $2 \mu \mathrm{m}$. Number 1 shows smooth reddened quartz of desert type; 2, subangular quartz; 3 , highly chemical altered quartz; 4, a close-up of 3 showing solution features and siliceous redeposition in the low right-hand corner; 5, smooth reddened quartz covered by palygorskite fibers; 6, a close-up of the fibrous coating; 7 , aeolized mica; and 8, wind-shaped palygorskite grain. after a residence time in the atmosphere of about 1 week and a journey over Atlantic Ocean of several hundred kilometers. Observations by Game [1964] at $600 \mathrm{~km}$ in the southwest of the Canary Islands report particles greater than $70 \mu \mathrm{m}$. Jaenicke and Schütz [1967] collected by impactor on Sal Island (Cape Verde Islands, $600 \mathrm{~km}$ from African coasts) particles with diameters between 20 and $200 \mu \mathrm{m}$. Glaccum and Prospero [1980] also indlcate quartz grains up to $90 \mu \mathrm{m}$ and mica flakes up to $350 \mu \mathrm{m}$ in diameter on Sal Island. During 2 years of sampling performed on the Cape Verde Islands, Schütz et al. [1977] found that particles greater than $100 \mu \mathrm{m}$ are still in suspension in the atmosphere at distances $1000 \mathrm{~km}$ off shores.

These observations indicate that in some cases, and contrary to classical considerations, coarse particles can be carried far away from their sources. This could be explained by the specific meteorological conditions which prevail during Saharan outbreak events. The April 6 outbreak dynamics illustrate this kind of situation: the vertical velocity indicates that the mixing may have extended to at least $2500 \mathrm{~m}$ height, where high winds $\left(30 \mathrm{~m} \mathrm{~s}^{-1}\right)$ allowed a long travel over Atlantic Ocean.

\section{Investigations on the Possible Source} Areas

The satellite images (for phase A) and air mass trajectories (for phase $A$ and $C$ ) give us an indication concerning the possible geographic origin of mineral dusts. These distinct source regions correspond also to particular chemical and mineralogical attributes of the dusts collected during these two phases.

Large percentages of the finest sizes of $\mathrm{SI}_{1}$ are shown in the episode $A$ samples, but these amounts are negligible in episode C (Figure 12). Now, from filter SEM examination, these fine particles are found to be mainly quartz. The occurrence of quartz less than $0.5 \mu \mathrm{m}$ has not been pointed out as yet in the 11terature.

Moreover, it seems that such fine quartz particles are a good indication of aeolian contribution source, and they are, generally spea$k$ ing, significant markers of the desert origin of dusts. Thus from some authors the aeolian mechanical erosion does give fine quartz particles (less than $0.5 \mu \mathrm{m}$ ). These may be distortions released from Impacts between sand grains [ $\mathrm{Krinsley}$ and MacCoy, 1978], which are very abundant in the 0.2 to $3.3-\mu m$ range, or they may represent cuttings resulting from crystalline rock corrosion by the strongest winds [Wilding et a1., 1977]. For these sizes a significant number of $S i$ flakes and chips may also be generated from quartz surficial amorphization of grains [Le Ribault, $1971 ; 1977$ ]. In the desert this is related to the impact of particles during saltation and rolling aeolian mobilization.

In other respects it seems that a great amount of such fine Si particles as those found in period A involves a geographic origin from areas where production and mobllization dust processes are very efficient; this occurs, of course, in 


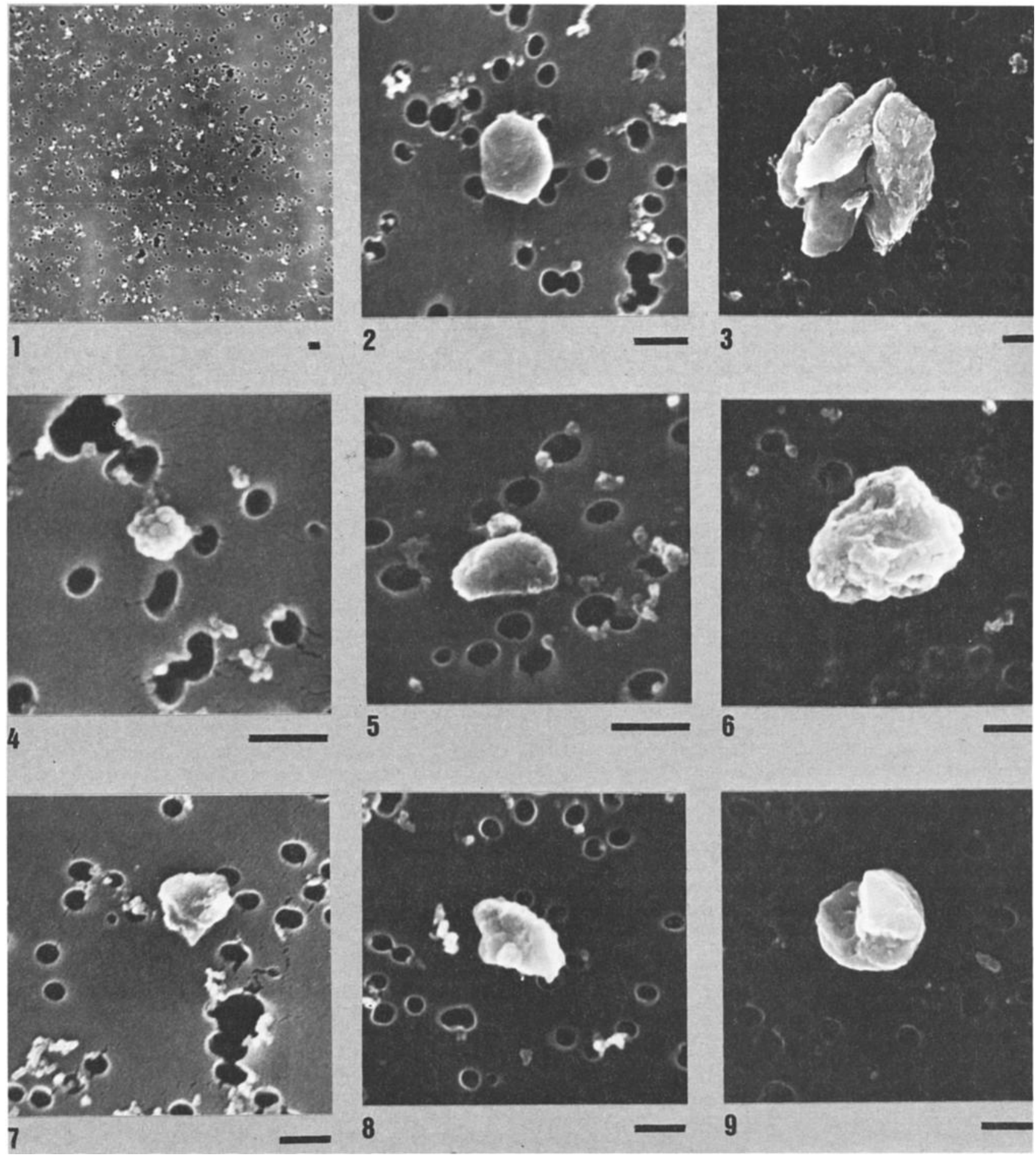

F1g. 14. Dust Trapped on Filters. Graphic scale is $1 \mu \mathrm{m}$. Number 1 Indicates general view of a filter; 2, a micaceous particle; 3, altered spindles of micrite; 4, a Si particle; 5 , a Ca particle; 6 , Al carbonate grain; 7 , an $\mathrm{Al}$, S1, Fe particle; 8 , small quartz; and 9 , a hematite grain.

desert areas without dense vegetation. This conclusion tallies with the outbreak of the April 6 period, where the origin area is the Souss alluvial flat, characterized by low, open, and scattered vegetation, and by noticeable free sand dunes. On the other hand, a low concentration of fine Si/quartz grains in episode $C$ may be understood by its geographic origin as being from more plant-covered regions of the Northern Atlantic
Atlas, where aeolian erosion and deflation processes are less efficient.

We note, in addition, the high content of calcite during phase $C$, compared to its concentration level during the phase $A$. This high level for calcite is in agreement with the difference of the source regions: for this period, air mass trajectories moved across major carbonated regions: the Atlantic Morocco plains or the Algero- 
Moroccan Sahara "hamadas," which are more regularly carbonated than the Souss plain or the Anti-Atlas, where the outbreak of April 6 began.

Finally, we must underline that the situation observed in our study is very propitious to the identification of the source regions. Thus in our cases these are located near the Atlantic coast, and consequently their mineralogical signature is not affected by mixing with other continental dusts. The outbreak of April 6 is also exceptlonal because only a limited and relatively small geographical area was concerned by this event. More generally, the lithometeors are not easily visible over Sahara during their initial phase. In more extreme cases, which of ten correspond to the greatest outputs of dust, the identification of the source region becomes much more difficult in relation to the large area covered by the phenomenon, because the mineralogical signature is not strong enough to appear after a long-range transport over the African continent. At this point, the concept of source region should give way to the concept of a global "North African" source.

\section{Conclusion}

This study provides information on transport processes and the source region of Saharan dust events which are of great interest for marine sedimentation in the African Atlantic margin and for the explanation of the origin of some Canary soil constituents. The connection of physical and chemical characterization of dust with air mass trajectories and remote sensing methods allows us to distinguish the different source regions of two dust outputs from African continent. The first one is associated with an outbreak event which took place in an area characterized by sand dunes (Souss plain) and a particular geochemical signature (fine quartz particles). The second one is consecutive to an air mass that moved over arid and semiarid areas which are more homogeneously carbonated (Hamadas in the Algero-Moroccan Sahara).

If these two African dust events can be distinguished by their mineralogical and chemical composition, they also correspond to different transport processes. The outbreak event arrived on Fuerteventura after a long travel of about 5 to 6 days over the Atlantic Ocean. The second one is associated with direct transport from the Moroccan coast in less than 1 day.

Concerning the impact of African dust on the marine sedimentation along the Atlantic African coasts and the Canary Islands, some specific points may be discussed.

The Role of Coarse Particles in Atmospheric Deposition Flux Budgets

The mathematical model from Schütz et al. [1981], which takes into account only the particles in the size range $0.1-20 \mu \mathrm{m}$, would indicate an upper limit for the particle size collected at $1000 \mathrm{~km}$ from the coastg of about $15 \mu \mathrm{m}$. At 100 $\mathrm{km}$ from the coasts, the maximal measured concentrations are obtained for a particle size close to $50 \mu \mathrm{m}$, i.e., larger than the limit of $20 \mu \mathrm{m}$ taken in the model. This 1 imit of $20 \mu \mathrm{m}$, also adopted by Gillette et al. [1978], is justifled by the lognormal size distribution of particles between 2 and $20 \mu \mathrm{m}$, whereas the coarse particles have a random statistical distribution. Arimoto et a1. [1985] and Uematsu et al. [1985] have shown from samples collected during Asian dust events at Enewetak atoll that the coarse mode, which represents only a few percent of the total mass, is sufficient to dominate the dry-deposition flux from the atmosphere to the ocean.

Problems in Obtaining an Exhaustive Dust Budget

Generally, in the calculation of dust budget over the Atlantic Ocean, only selected spectacular outbreaks have been treated. These have been observed either on satellite images or recognized by the fact that they generate massive dust falls. Now, for the study period, phase A can be effectively observed on NOAA images, but from April 17 until 19, dust falls could be sampled, although the dust clouds were neither massive or visible in satellite photos. On the other hand, a return of air masses and particles toward the African continent after passing over Fuerteventura is observed from trajectorles of the first phase. That is in accordance with the budget proposed by Schütz et al. [1981], who estimate a return of about 60 millions of metric tons of Saharan dust out of $260 \mathrm{t}$ exported towards Atlantic Ocean.

Acknowledgments. The authors are grateful to the Spanish authorities and especially to Gerardo Mesa, Cabildo of Fuerteventura Island, for their full support. We would like to mention the friendly cooperation of P. Blanc and D. Rivaille for $X$ ray determinations and SEM examination, and $P$. Buat-Ménard, J. Davis and F. Dulac for their critical review. This work was supported by the Centre National de la Recherche Scientifique (France).

\section{References}

Arimoto, R., R. A. Duce, B. J. Ray, and C. K. Unni, Atmospheric trace elements at Enewetak Atol1, 2, Transport to the ocean by wet and dry deposition, J. Geophys. Res., 90, 2391$2408,1985$.

Bergametti, G., R. Vié le Sage, B. Grubis, B. Dulieu, and C. Ellchegaray, Relation between particulate concentration in the atmosphere and aerosol collection efficiency, Environ. Technol. Lett., 3, 297-304, 1983.

Bertrand, J., J. Baudet, and A. Drochon, Importance des aérosols naturels en Afrique de 1'Ouest, J. Rech. Atmos., 8, 845-860, 1974.

Buat-Ménard, P., and R. Chesselet, Variable Influence of the atmospheric fluxes on the trace metal chemistry of oceanic suspended matter, Earth Planet. Sci. Lett., 42, 399-411, 1979.

Car 1son, T. N., Atmospheric turbidity in Saharan dust outbreaks as determined by analyses of satellite brightness data, Mon. Weather Rev., $107,322-335,1979$.

Carison, T. N., and S. G. Benjamin, Radiative heating rates for Saharan dust, J. Atmos. Sci., 37, 193-213, 1980.

Car1son, T. N., and J. M. Prospero, The largescale movement of Saharan air outbreaks over 
the Northern Equatorial Atlantic, J. App1. Meteorol., 11, 283-297, 1972.

Chamley, H., G. Coudé-Gaussen, P. Debrabant, and P. Rognon, Contribution autochtone et allochtone à la sédimentation quaternaire de l'ile de Fuerteventura (Canaries), Bull. Soc. Géol. Fr., in press, 1987.

Chester, R., and L. R. Johnson, Atmospheric dusts collected off the West African coast, Nature, 229, 105-107, 1971.

Chester, R, , H. Ederfield, J. J. Griffin, L. R. Johnson, and R. C. Padgham, Eolian dust along the eastern margins of the Atlantic Ocean, Mar. Geol., 13, 91-105, 1972.

Chester, R., A. G. Griffiths, and J. M. Hirst, The influence of soil-sized atmospheric particulates on the elemental chemistry of the deep-sea sediments of the North Eastern Atlantic, Mar. Geol., 32, 141-154, 1979.

Chester, R., E. J. Sharples, G. S. Sanders, and A. C. Saydam, Saharan dust incursion over the Tyrrhenian Sea, Atmos. Environ., 18, 929-935, 1984.

Coudé-Gaussen, G., Etude détalllée d'un échantillon de poussiéres éoliennes prélevé au Tanezrouft le 10 Décembre 1980, Rech. Geogr. Strasbourg, 16/17, 121-130, 1981.

Coude-Gaussen, G., Les poussières éoliennes sahariennes: Mise au point, Rev. Geomorphol. Dyn., $31,49-69,1982$.

Coude-Gaussen, G., Le cycle des poussières éollennes désertiques actuelles et la sédimentation des loess péridésertiques quaternaires, Bu11. ELF Aquit., 8, 167-182, 1984.

Coude-Gaussen, G., and P. Blanc, Présence de grains éolisés de palygorskite dans les poussières actuelles et les sédiments récents d'origine désertique, Bull. Soc. Geol. Fr., $\underline{8}$, $571-579,1985$.

Coudé-Gaussen, G., and P. Rognon, Les poussières sahariennes, La Recherche, 147, 1050-1062, 1983.

D'Almeida, G., and L. Schütz, Number, mass and volume distributions of mineral aerosol and solls of the Sahara, J. Clim. Appl. Meteorol., 22. 233-243, 1983.

Delany, A. C., D. W. Parkin, J. J. Griffin, E. D. Goldberg, and B. E. Reimann, Airbone dust collected off the West African coast, Geochim. Cosmochim. Acta, 31, 885-909, 1967.

Domergue, J. L., Contribution a l'étude de l'aérosol atmosphérique en région intertropicale, doctoral thesis, Univ. of Toulouse, France, 1980 .

Duce, R. A., G. L. Hoffman, and W. H. Zoller, Atmospheric trace metals at remote northern and southern hemisphere sites: Pollution or natural?, Science, $187,59-61,1975$.

Dulac, F., Dynamique du transport et des retombées d'aérosols en Méditerranée occidentale, thesis, 241 pp., Univ, of Paris 7, 1986.

Elichegaray, C., A. L. Dutot, B. Grubis, and R. Vié le Sage, Dosage par fluorescence $X$ des aérosols atmosphériques, Analusis, 10, 492497, 1981.

Fernandez-Navarro, L., A proposito de una caida de polvo en Canarias, R. Soc. Esp. Hist. Nat.. $47,436-445,1921$.

Game, P. M., Observations on a dust fall in the eastern Atlantic, February 1962, J. Sediment. Petrol., 34, 355-359, 1964.
Gillette, D. A., R. N. Clayton, T. K. Mayeda, M. L. Jackson, and K. Sridhar, Tropospheric aerosols from some major dust storms of the southwestern United States, J. App1. Meteorol., 17, 832-845, 1978.

Glaccum, R. A., and J. M. Prospero, Saharan aerosols over the tropical North Atlantic. Mineralogy., Mar. Geol., 37, 295-321, 1980.

Huetz de Lemps, A., Le climat des îles Canaries, Sedes, T.54, 226 pp., Paris, 1969.

Jaenicke, R., Aitken particle size distribution in the Atlantic north east trade winds, Meteor Forschungsergeb. Reihe B, 13, 1-9, 1978 .

Jaenicke, R., and L. Schütz, Studien zur oberen grenzgrösse des natülichen aerosoles, Contrib. Atmos. Phys., 40, 129-143, 1967 :

Julien, R., R. Botet, and $\bar{M}$. Kolb, Les agrégats, La Recherche, 171, 1334-1343, 1985.

Krinsley, D. H., and F. MacCoy, Aeolian quartz sand and silt, in Scanning Electron Microscopy in the Study of Sediments, pp. 249-260, Geoabstract, Norwich, England, 1978.

Lange, H., Distribution of chlorite and kaolinfte in eastern Atlantic sediments off North Africa, Sedimentology, 29, 427-431, 1982.

Lepple, F. K., Aeollan dust over the North Atlantic ocean, Ph.D. thesis, 270 pp., Univ. of Del., Newark, 1975.

Le Ribault, L., Présence d'une pellicule de silice amorphe a la surface de cristaux de quarta des formations sableuses, C. R. Seances Acad. Sc1., 272, 1933-1936, 1971 .

Le Ribault, L., L'exoscople des quartz, 150 pp., Masson, Paris, 1977.

Logan, J., African dusts as a source of solutes in Gran Canarian ground waters, Geol. Soc. Am. Bull., 6, 849, 1974 .

MacTainsh, G. $\vec{H}_{.}$, and P. H. Walker, Nature and distribution of Harmattan dust, z. Geomorph. N. F. , 26, 417-435, 1982 .

Martin, D., D. Cheymol, M. Imbard and B. Strauss, Classement automatique des trajectoires du panache de 1'Etna - Etude climatologique, in Physico-chemical Behaviour of Atmospheric Pollutants, pp. 635-648, D. Reidel, Hingham, Mass., 1984 .

Morales, C. (Ed.), Saharan dust: Mobilization, Transport, Deposition (SCOPE 14) 297 PP., John Wiley, New York, 1979.

0liva, P., G. Coudé-Gaussen, H. Delannoy, L. Dorize, P. Rognon, and M. Tabeaud, Etude de la dynamique de quelques lithométéores sahariens par télédétection spatiale, Méditerranée, $\underline{3}$, $21-52,1983$.

Parkin, D. W., D. R. Philips, R. A. Sullivan, and L. R. Johnson, Airbone dust collections down the Atlantic, Q. J. R. Meteorol. Soc., 98, 798-808, 1972 .

Prospero, J. M., Mineral and sea-salt aerosol concentrations in various ocean regions, J. Geophys. Res., 84, 725-731, 1979.

Prospero, J. M., and T. N. Carlson, Vertical and areal distribution of Saharan dust over the western equatorial North Atlantic ocean, J. Geophys. Res., 77, 5255-5265, 1972.

Rahn, K. A., Silicon and aluminium in atmospheric aerosols: Crust- air fractionation?, Atmos. Environ., 10, 597-601, 1976.

Rahn, K. A., L. Schütz, and R. Jaenicke, Elemental composition of Sahara aerosol and Sahara 
soil, Bul1. Am. Meteorol. Soc., 57, 146-158, 1976.

Sarnthein, M., J. Thiede, U. Pflaumann, H. Erlenkeuser, D. Fütterer, B. Koopmann, H. Lange, and E. Seibold, Atmospheric and oceanic patterns off Northwest Africa during the past 25 million years, in Geology of the Northwest African Continental Margin, edited by U. Von Rad, K. Linz, M. Sarnthein, and E. Seibold, pp. 545-604, 1982.

Schütz, L., Long-range transport of desert dust with special emphasis on the Sahara, Ann. N.Y. Acad. Sci., 338, 515-532, 1980.

Schütz, L., and R. Jaenicke, Particle number and mass distribution above $10^{-4} \mathrm{~cm}$ radius in sand and aerosols of the Sahara desert, J. Appl. Meteorol., 13, 863-870, 1974.

Schütz, L., R. Jaenicke, and H. Pietrek, Saharan dust transport over the North Atlantic Ocean, Geol. Soc. of Amer., special paper 186, $87-100,1981$.

Tetzlaff, G., and K. Wolter, Meteorological patterns and the transport of mineral dust from the North African continent, in Paleoecology of Africa, vol. 12, Sahara and Surrounding Seas, edited by $M$. Sarthein, E. Seibold and P. Rognon, pp.31-42, 1980.

Tobias, C., and C. Megile, Les 1ithométhéores au Tchad. Premiers resultats concernant la nature, la composition et l'importance des aérosols transportés par voie atmosphérique dans la région de N'D jamena (Tchad), Cah. ORSTOM Ser. Pedol., 18, 71-81, 1981.

Turekian, K. K., Geochemical distribution of elements, in Mc Graw-Hill Encyclopedia of Science and Technology, vol. 4, pp. 627-630, 1971 .

Uematsu, M., R. A. Duce, S. Nakaya, and S.
Tsunogaï, Short-term temporal variability of eolian particles in surface waters of the Northwestern North Pacific, J. Geophys. Res. 90, 1167-1172, 1985.

Whatley, W. B., and B. J. Smith, Mineral content of harmattan dust from Northern Nigeria examined by scanning electron microscopy, J. Arid Environ., 4, 21-29, 1981.

Wilding, L., N. Smeck, and L. Drees, Sillca in soils: quartz, cristoballite, tridymite and opal, in Minerals in Soil Environments, edited by J. Dixon and S. Weed, Madison, Wisc., 1977.

Wilke, B. M., B. J. Duke, and W. L. Jimoh, Mineralogy and chemistry of harmattan dust in northern Nigeria, Catena, 11, 91-96, 1984.

Windom, H. L., Aeolian contributions to marine sediments, J. Sediment. Petrol., 45, 520-529, 1975.

G. Bergametti and L. Gomes, Laboratoire de Physico-Chimie de l'Atmosphère, Université Paris VII, 2 Place Jussieu, 75251 Paris Cedex 05, France.

G. Coude-Gaussen and P. Rognon, Unité Associée 722, Centre National de la Recherche Sclentifique, Université Pierre et Marie Curie, 4 Place Jussieu, 75252 Paris Cedex 05, France.

J. M. Gros and B. Strauss, Météorologie Nationale, 2 Avenue Rapp, 75340 Paris Cedex 07, France.

M. N. Le Coustumer, Centre de Géomorphologie du Centre National de la Recherche Scientifique, Rue des Tilleuls, 14000 Caen, France.

(Received July 22, 1986; revised June 2, 1987; accepted June $4,1987$. ) 